\title{
Elucidating the Significance of $\beta$-Hydride Elimination and the Dynamic Role of Acid/Base Chemistry in a Palladium-Catalyzed Aerobic Oxidation of Alcohols
}

\author{
Jaime A. Mueller, Christopher P. Goller, and Matthew S. Sigman ${ }^{\star}$ \\ Contribution from the Department of Chemistry, University of Utah, 315 South 1400 East, Salt Lake \\ City, Utah 84112
}

\begin{abstract}
The mechanistic details of aerobic alcohol oxidation with catalytic $\mathrm{Pd}(\mathrm{Ii} P r)(\mathrm{OAc})_{2}\left(\mathrm{H}_{2} \mathrm{O}\right)(\mathrm{Ii} \mathrm{Pr}=1,3-$ bis(2,6-diisopropylphenyl)imidazol-2-ylidene) are disclosed. Under optimal conditions, $\beta$-hydride elimination is rate-limiting supported by kinetic studies including a high primary kinetic isotope effect (KIE) value of $5.5 \pm 0.1$ and a Hammett $\rho$ value of $-0.48 \pm 0.04$. On the basis of these studies, a late transition state is proposed for $\beta$-hydride elimination, which is further corroborated by theoretical calculations using density functional theory. Additive acetic acid modulates the rates of both the alcohol oxidation sequence and regeneration of the Pd catalyst. With no additive [HOAc], turnover-limiting reprotonation of intermediate palladium peroxo is kinetically competitive with $\beta$ hydride elimination, allowing for reversible oxygenation and decomposition of $\operatorname{Pd}(0)$. With additive [HOAc] ( $>2 \mathrm{~mol} \%$ ), reprotonation of the palladium peroxo is fast and $\beta$-hydride elimination is the single rate-controlling step. This proposal is supported by an apparent decomposition pathway modulated by [HOAc], a change in alcohol concentration dependence, a lack of $\left[\mathrm{O}_{2}\right]$ dependence at high [HOAc], and significant changes in the KIE values at different HOAc concentrations.
\end{abstract}

\section{Introduction}

The observation that alcohols are oxidized by $\mathrm{Pd}(\mathrm{II})$, or at least that $\mathrm{Pd}(\mathrm{II})$ is reduced to $\mathrm{Pd}(0)$ in the presence of an alcohol, was first made over 175 years ago when Berzelius observed Pd metal precipitate out of a heated alcoholic solution of Pd(II). ${ }^{1}$ While the use of stoichiometric $\mathrm{Pd}(\mathrm{II})$ as an oxidant is not a practical approach to oxidizing alcohols, ${ }^{2}$ the ability to use a catalytic amount of $\mathrm{Pd}(\mathrm{II})$, along with a stoichiometric amount of a simple oxidant, such as molecular oxygen, to reoxidize the $\operatorname{Pd}(0)$ is highly attractive. ${ }^{3}$ Moiseev was the first to report a Pd-catalyzed oxidation of an alcohol under aerobic conditions in the presence of $\mathrm{CuCl}_{2}$ in 1963. ${ }^{4}$ In 1967, Lloyd disclosed a study of Pd-catalyzed aerobic oxidations of alcohols focusing largely on the role of additives to facilitate the reoxidation of $\mathrm{Pd}^{5}{ }^{5}$ The most important observation made in this study was catalytic amounts of $\mathrm{PdCl}_{2}$, without any additive, could facilitate the oxidation of alcohols under aerobic conditions although with very low efficiency. In 1977, Blackburn and Schwartz were the first to develop a synthetically useful procedure for the oxidation of alcohols under aerobic conditions without a copper additive. ${ }^{6}$ In their procedure, $1 \mathrm{~mol} \% \mathrm{PdCl}_{2}$ and $5 \mathrm{~mol} \% \mathrm{NaOAc}$ are used under the relatively mild conditions of $1 \mathrm{~atm}$ of $\mathrm{O}_{2}$ at $38^{\circ} \mathrm{C}$ in ethylene carbonate as solvent for the oxidation of a variety of alcohols.

(C) 2004 American Chemical Society

E-mail: E-mail: sigman@chem.utah.edu.

Supporting Information Available: Statistical analyses, rate tables, rate law derivation, preparation of catalyst derivatives, DFT calculation data, and NMR spectra (PDF). This material is available free of charge via the Internet at http://pubs.acs.org. 
The major drawback to this procedure is the long reaction times required for high conversions (typically $\sim 100 \mathrm{~h}$ ).

It was not until 1998 that two groups reported significant improvements in palladium-catalyzed aerobic oxidation of alcohols. The first was reported by Peterson and Larock, ${ }^{7}$ who found the use of $5 \mathrm{~mol} \% \mathrm{Pd}(\mathrm{OAc})_{2}$, in combination with an appropriate carbonate base, provides an effective catalyst system for the oxidation of benzylic and allylic alcohols when DMSO is used as solvent at $1 \mathrm{~atm}$ of $\mathrm{O}_{2}$ and $80{ }^{\circ} \mathrm{C} .{ }^{8-10}$ The second is a $\mathrm{Pd}(\mathrm{OAc})_{2} /$ pyridine catalyst system developed by Uemura and co-workers. ${ }^{11}$ In this system, $5 \mathrm{~mol} \% \mathrm{Pd}(\mathrm{OAc})_{2}, 20 \mathrm{~mol} \%$ pyridine, and activated $3 \AA$ molecular sieves prove an effective combination for the oxidation of benzylic and aliphatic alcohols at $1 \mathrm{~atm}$ of $\mathrm{O}_{2}$ and $80^{\circ} \mathrm{C}$. For allylic alcohols, greater amounts of pyridine are required for efficient oxidation. In addition to displaying good substrate scope, high conversions are achieved in relatively short times $(\sim 2 \mathrm{~h})$ for most substrates. Uemura and others have extended this oxidation system to a variety of other interesting transformations. ${ }^{12-16}$

Since the reemergence of Pd-catalyzed aerobic oxidations of alcohols, several other groups have reported new catalysts. Sheldon and co-workers have developed a system for the oxidation of alcohols in aqueous solutions using a water-soluble phenanthroline ligand. ${ }^{17}$ The reaction is carried out under forcing conditions, $100{ }^{\circ} \mathrm{C}$ and $30 \mathrm{~atm}$ of air pressure, but these conditions do allow the use of rather low palladium catalyst loadings (typically $0.1-0.5 \mathrm{~mol} \%$ ). Moberg and co-workers have developed a catalyst system using an oxazoline-pallada-cycle complex. ${ }^{18}$ While this reaction is not as efficient as some of the previous examples, it is important as the first example of a homogeneous Pd catalyst for alcohol oxidation using ambient air atmosphere instead of pure $\mathrm{O}_{2} \cdot{ }^{19} \mathrm{We}$ have developed the first method for Pd-catalyzed aerobic alcohol oxidation at room temperature using $3 \mathrm{~mol} \% \mathrm{Pd}(\mathrm{OAc})_{2}$ and $6 \mathrm{~mol} \%$ triethylamine with a scope similar to that of Uemura's system. ${ }^{20,21}$ While excellent progress has been made in catalyst development for palladium-catalyzed aerobic oxidation of alcohols, all suffer from high catalyst loadings, the use of high pressures of $\mathrm{O}_{2}$, and/or high temperatures.

With clear limitations in reported palladium-catalyzed aerobic oxidations of alcohols, we sought to develop a more active and robust catalyst. The basis of this effort was to take recently reported mechanistic information on the fundamental steps involved to design an improved catalyst. Key observations include (1) Pd(0) species decompose during regeneration of the $\mathrm{Pd}$ catalyst without adequate support by ligand and/or solvent, (2) excess amine ligand inhibits alcohol oxidation, and (3) base is mandatory for alcohol oxidation. Stahl's investigations of Larock's ${ }^{22}$ and Uemura' ${ }^{23}$ systems highlighted the need for substantial support of $\operatorname{Pd}(0)$ species during regeneration of the catalyst. In Larock's system, the soft, donating character of the solvent dimethyl sulfoxide was found to have a stabilizing effect to prevent aggregation of $\mathrm{Pd}(0)$ species. In Uemura's $\mathrm{Pd}(\mathrm{OAc})_{2} /$ pyridine and our $\mathrm{Pd}(\mathrm{OAc})_{2} /$ triethylamine aerobic alcohol oxidations, excess amine ligand is necessary for a competent oxidation presumably through stabilization of $\mathrm{Pd}(0)$ intermediates. A caveat to this is excess amine ligand also inhibits alcohol oxidation, leading to the need for higher catalyst loadings (3-5 mol \%) for effective oxidations. Investigations of these systems indicate that the inhibition is most likely due to either competitive binding of the amine with the alcohol substrate or the need to dissociate an amine ligand to allow for rate-limiting $\beta$-hydride elimination. ${ }^{20,23}$ An additional role of amine ligand is as an exogenous Brønsted base to deprotonate a palladium-bound alcohol to form a palladium alkoxide for subsequent $\beta$-hydride elimination. ${ }^{24}$

On the basis of this analysis, the two design elements for improved aerobic alcohol oxidation catalysts are (1) a monodentate ligand to support Pd species involved and to provide a readily accessible coordination site to lower the energy barrier for rate-limiting $\beta$-hydride elimination and (2) a base that does not inhibit the oxidation. For ligand selection, N-heterocyclic carbene (NHC) ligands meet the above criteria and have proven effective in various $\operatorname{Pd}(0)$-catalyzed 
processes $^{25}$ as well as an oxidative kinetic resolution using (-)-sparteine as the exogenous base. ${ }^{26}$ Acetate was also selected as a ligand for Pd(II) to serve both as a counterion and as a Brønsted base to deprotonate the Pd-bound alcohol. ${ }^{24 b, c}$ Since the acetate base would be masked as an anionic ligand, an intriguing possibility is acetate could facilitate an intramolecular deprotonation (Scheme 1).

To test the catalyst design, $\left[\mathrm{Pd}(\mathrm{Ii} \mathrm{Pr}) \mathrm{Cl}_{2}\right]$ dimer ( $\mathrm{I} i \mathrm{Pr}=1,3$-bis(2,6-diisopropylphenyl) imidazol-2-ylidene) was submitted to AgOAc metathesis to form the monomeric complex $\mathrm{Pd}$ $(\mathrm{IiPr})(\mathrm{OAc})_{2}\left(\mathrm{H}_{2} \mathrm{O}\right), \mathbf{1}$. At $5 \mathrm{~mol} \%$, this complex was effective in oxidizing sec-phenethyl alcohol to acetophenone with $>99 \%$ conversion in less than $2 \mathrm{~h}$ at $50{ }^{\circ} \mathrm{C}$. Upon discovery of such an active catalyst, the system was optimized to lower catalyst loadings. The optimized catalytic system includes $0.5 \mathrm{~mol} \% \mathbf{1}, 2 \mathrm{~mol} \% \mathrm{HOAc}$, and $3 \AA$ molecular sieves in toluene at $60{ }^{\circ} \mathrm{C}$ under a balloon pressure of $\mathrm{O}_{2}$ (Figure 1). ${ }^{27}$ For activated substrates, up to 1000 turnovers can be accomplished, representing one of the most effective Pd catalysts for aerobic alcohol oxidation reported to date. This system converts primary and secondary benzylic, allylic, and aliphatic substrates to aldehydes and ketones in high yields. The robustness of the catalyst is demonstrated by the effective oxidation of alcohols using an ambient air atmosphere.

Considering the unique activity of this catalyst and the mechanistic approach used for the discovery, we set out to confirm the rationale of the catalyst design through mechanistic studies. In addition, one anomalous additive, acetic acid, was necessary for consistent oxidation. Herein, we describe a detailed investigation of the nature of $\beta$-hydride elimination through experiment and theory as well as identification of the dynamic role of acid/base chemistry.

\section{Results and Discussion}

A general proposed mechanism for the aerobic oxidation of alcohols with $\mathbf{1}$ is depicted in Scheme 2. Dissociation of water to form A initiates the catalytic cycle with the water presumably trapped by molecular sieves. Alcohol substrate $\mathbf{2}$ binds to A, forming Pd-bound alcohol $\mathbf{B}$. Intramolecular deprotonation of $\mathbf{B}$ forms palladium alkoxide $\mathbf{C}$ followed by subsequent $\beta$-hydride elimination to expunge carbonyl product and form palladium hydride D. This sequence will be referred to as the alcohol oxidation realm of the catalytic cycle. Palladium hydride $\mathbf{D}$ undergoes reductive elimination of acetic acid to yield $\operatorname{Pd}(0)$ species $\mathbf{E}$. $\mathbf{E}$ is oxygenated to $\mathrm{Pd}$ (II) by molecular oxygen to produce palladium peroxo $\mathbf{F}$, which is protonated by acetic acid to re-form $A$ and 1 equiv of $\mathrm{H}_{2} \mathrm{O}_{2}$. This sequence will be referred to as the $\mathrm{Pd}(\mathrm{II})$ catalyst regeneration realm of the catalytic cycle.

A key preliminary step in elucidating the mechanistic details was structural characterization of 1. A single crystal was grown from dichloromethane/hexanes. X-ray crystallographic analysis revealed a square planar structure with the carbene ligand bound monodentate and an acetate counterion on each side (Figure 2). ${ }^{27}$ Interestingly, the oxygen of a water molecule is datively bound to fill the last coordination site on Pd trans to the carbene. Additionally, the hydrogen atoms on the water molecule are bound to the carbonyl oxygen of each acetate ligand. This hydrogen-bonding phenomenon supports the proposal of an intramolecular deprotonation of the Pd-bound alcohol through the assistance of hydrogen bonding to the acetate carbonyl oxygen.

To determine whether the water molecule was an artifact of crystallization or if it was incorporated as the complex formed, the isolated crystalline complex was examined by ${ }^{1} \mathrm{H}$ NMR. The ${ }^{1} \mathrm{H}$ NMR spectrum of the crystallized material in $\mathrm{CDCl}_{3}$ was identical to that of the initial complex used. This suggests that they are the same complex; however, the expected peak of a bound water molecule was not observed in either spectrum. To address this discrepancy, the crystallized complex was studied from -60 to $0{ }^{\circ} \mathrm{C}$ by variable- 
temperature ${ }^{1} \mathrm{H}$ NMR at $20{ }^{\circ} \mathrm{C}$ intervals (Figure 3). This set of spectra clearly displays a broad peak emerging as the temperature is decreased below $0{ }^{\circ} \mathrm{C}$. The peak sharpens with a further decrease in temperature until it appears as a singlet at $\sim 8.6 \mathrm{ppm}$ at $-60^{\circ} \mathrm{C}$, demonstrating the inclusion of a water molecule in solution.

\section{Kinetic Characterization of Optimized Conditions}

Using in situ Fourier transform infrared spectroscopy to measure oxidation rates, initial kinetic studies revealed the alcohol oxidation sequence is rate limiting under slightly modified optimal conditions $^{28}$ with first-order dependencies on $[\mathbf{1}]^{29}$ and sec-phenethyl alcohol concentration. Large primary kinetic isotope effects (KIEs) of $5.5 \pm 0.1$ for sec-phenethyl alcohol and $5.5 \pm$ 0.5 for 2-decanol oxidation were observed, which are consistent with rate-limiting $\beta$-hydride elimination. Due to the unusual magnitude of these KIE values (vide infra), a Hammett plot was constructed to evaluate the electronic effects at the benzylic center (eq 1).${ }^{30} \mathrm{~A}$ linear free energy relationship was observed with a calculated $\rho$ value of $-0.48 \pm 0.04$ (Figure 4 ). The negative $\rho$ value signifies a positive charge buildup in the transition state, further supporting rate-limiting $\beta$-hydride elimination.

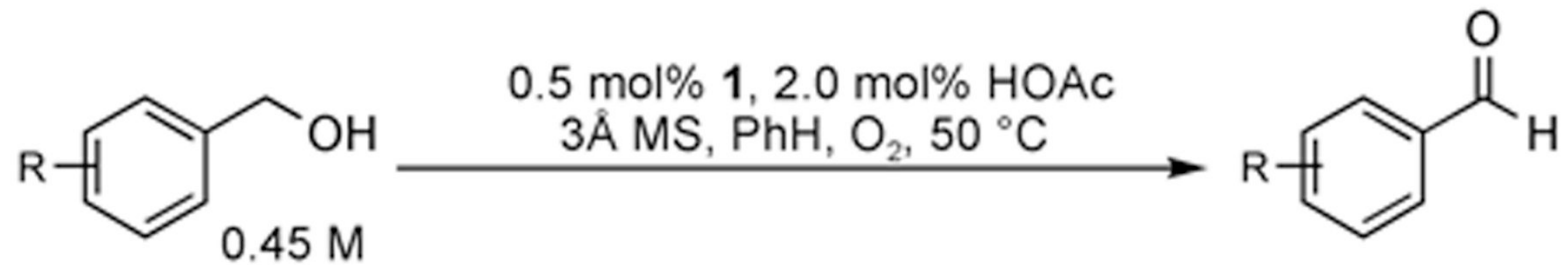

$\mathrm{R}=p$-OMe, $p$-Me, $\mathrm{H}, p-\mathrm{Cl}, m-\mathrm{OMe}, p-\mathrm{CF}_{3}$

\section{Nature of $\beta$-Hydride Elimination}

The initial kinetic evidence establishes $\beta$-hydride elimination as rate determining. However, the substantial magnitude of the measured KIE value $(5.5 \pm 0.1$ for sec-phenethyl alcohol oxidation) implicates the nature of $\beta$-hydride elimination is unique compared to that of ratelimiting $\beta$-hydride elimination in other Pd-catalyzed alcohol oxidations. Significantly smaller KIE values have been measured for these other systems, which include a KIE of $1.31 \pm 0.04$ we reported for the oxidation of (S)-sec-phenethyl alcohol with Pd(II)/(-)-sparteine, ${ }^{24 \mathrm{~b}, \mathrm{c}}$ a KIE of $1.3 \pm 0.1$ reported by Stahl et al. in evaluating Uemura's $\mathrm{Pd}(\mathrm{II}) /$ pyridine-catalyzed oxidation of benzyl alcohol $(0.1 \mathrm{M}),{ }^{23}$ and a KIE of 1.4 reported by Sheldon et al. for the Pd(II)/ bathophenanthroline disulfonate-catalyzed oxidation of sec-phenethyl alcohol. ${ }^{17 \mathrm{c}}$

This considerable disparity in KIE values measured for the monodentate carbene system and other Pd-catalyzed aerobic alcohol oxidation systems can provide insight into the modulation of $\beta$-hydride elimination. The catalyst was designed predicting the monodentate ligand leaves an accessible coordination site for $\beta$-hydride elimination, thereby altering the reactivity of the catalyst and the nature of the transition state. The high KIE value for this system indicates a transition state with minimal vibrational energy differences, maximizing $\Delta \Delta G^{\ddagger}$ between $\alpha-\mathrm{H}$ and $\alpha$-D sec-phenethyl alcohol. Traditionally, linear, symmetric transition states are the models for systems with high KIE values because bond vibrations are minimal in the transition state. ${ }^{31}$ However, it is difficult to imagine a linear transition state for $\beta$-hydride elimination which leads to another model to describe the observed large KIE values. ${ }^{32}$ 
A high KIE value can be measured when the vibration in the transition state is minimal and/ or the difference in vibrational energy levels in the transition state is small. ${ }^{33}$ Both criteria for a high KIE are met when the transition state is late in this transformation with almost complete $\mathrm{C}-\mathrm{H}(\mathrm{C}-\mathrm{D})$ bond cleavage and $\mathrm{Pd}-\mathrm{H}(\mathrm{Pd}-\mathrm{D})$ bond formation. The magnitude of vibration and the difference in vibrational energy levels in the transition state are minimized when the weaker bond of hydrogen with a significantly heavier atom, $\mathrm{Pd}-\mathrm{H}$ (bond stretching frequency 1953 $\mathrm{cm}^{-1}$ ), ${ }^{34}$ is more fully formed and the stronger bond of hydrogen to a lighter atom, $\mathrm{C}-\mathrm{H}$ (bond stretching frequency $2900 \mathrm{~cm}^{-1}$ ), is nearly cleaved (Figure 5). A readily accessible coordination site on $\mathrm{Pd}(\mathrm{II})$ should facilitate a late transition state. This contrasts with other Pdcatalyzed alcohol oxidations where a ligand saturates the coordination sphere. As a comparison, (-)-sparteine binds datively to Pd(II) in two coordination sites; the other two sites are occupied by anionic ligands (either chloride or alkoxide), rendering the square planar coordination sphere saturated (Figure 6). Two limiting scenarios can be envisioned for $\beta$-hydride elimination: (1) a dissociative pathway where a ligand/counterion dissociates completely prior to rate-limiting $\beta$-hydride elimination or (2) an associative pathway where the $\beta$-hydride and the ligand/counterion are partially coordinated to $\mathrm{Pd}(\mathrm{II})$ in the transition state. In the former case, a KIE similar to that of the $\mathrm{Pd}(\mathrm{Ii} \operatorname{Pr})(\mathrm{OAc})_{2}\left(\mathrm{H}_{2} \mathrm{O}\right)$ system where a late transition state is proposed would be expected if $\beta$-hydride elimination remained rate limiting. For the latter case, there is not a readily accessible coordination site for $\beta$-hydride elimination; thus, the carbonyl product and palladium hydride are formed through a 5-coordinate transition state. In this scenario, the transition state is earlier, where $\mathrm{H}(\mathrm{D})$ is bound more to the carbon atom than to $\mathrm{Pd}(\mathrm{II})$, leading to a greater separation of the vibrational energy levels in the transition state and lowering the observed KIE values. Therefore, this associative substitution (5-coordinate transition state) scenario is most consistent with the smaller observed KIE values for both the Pd-catalyzed oxidative kinetic resolution of alcohols using (-)-sparteine and Uemura's Pd(II)/ pyridine alcohol oxidation system. ${ }^{35}$

Other experimental evidence also highlights the differences between the oxidation of alcohols with 1 and $\mathrm{Pd}[(-)$-sparteine $]-\mathrm{Cl}_{2}$. Although a $\rho$ value of $-0.48 \pm 0.04$ measured for the oxidation of substituted benzyl alcohols with 1 supports rate-limiting $\beta$-hydride elimination, it differs significantly from the value measured using $\operatorname{Pd}[(-)$-sparteine $] \mathrm{Cl}_{2}(\rho=-1.41 \pm 0.15) .{ }^{24 \mathrm{~b}}$ The smaller $\rho$ value of $-0.48 \pm 0.04$ observed for oxidation of alcohols with 1 indicates that electronics have a relatively subtle influence on $\beta$-hydride elimination. This is consistent with the proposed late-transition-state model (Figure 5 and Figure 6 ) where positive charge buildup stabilization is less important for facile oxidation. For the $\mathrm{Pd}(\mathrm{II}) /(-)$-sparteine system, electrondonating groups clearly play a more important role by stabilizing the positive charge generated in the transition state, increasing the nucleophilicity of the hydride.

To further understand the unusually high KIE values and to gain a more detailed understanding of $\beta$-hydride elimination, computational studies using density functional theory were undertaken. The geometries of $\mathrm{Pd}(\mathrm{I} i \mathrm{Pr})(\mathrm{OAc})$ species $\mathbf{2 C}, \mathbf{2 C}^{\ddagger}$, and $\mathbf{2 D ^ { 3 6 }}$ (Figure 7) were fully optimized in the Gaussian ${ }^{37}$ program using B3LYP ${ }^{38,39}$ and the LANL2DZ ${ }^{40,41}$ basis set, which includes relativistic effective core potentials. ${ }^{42,43}$ The geometry of $\mathbf{2 C}$ was elucidated using the QST2 $2^{44}$ search method. Frequency calculations were used to determine $\Delta G_{\mathrm{H}^{\ddagger}}$ and $\Delta G_{\mathrm{D}}^{\ddagger}$. All energies reported include zero-point and entropy corrections for the experimental temperature and pressure $(323.15 \mathrm{~K}$ and $1 \mathrm{~atm}) .{ }^{45}$ Examination of key bond lengths and angles revealed the ground-state palladium alkoxide $\mathbf{2 C}$ has an optimized geometry very similar to that of the solved crystal structure of $\mathbf{1}$ (Figure 2).

The calculated transition state, $\mathbf{2} \mathrm{C}^{\ddagger}$, correlates well with our proposed product-like transitionstate model. Comparison of the bond lengths $\mathrm{Pd}-\mathrm{H} 1$ and $\mathrm{C} 2-\mathrm{H} 1$ in the three structures reveals that the transition state is more comparable to product $\mathbf{2 D}$ than to palladium alkoxide ground state 2C (Table 1). The Pd-H1 distance is $2.70 \AA$ in the ground state $\mathbf{2 C}$, while the $\mathrm{Pd}-\mathrm{H} 1$ 
bond length in 2D is $1.57 \AA$. The $\mathrm{Pd}-\mathrm{H} 1$ distance is only $1.60 \AA$ in $\mathbf{2 C}$, indicating the hydride is nearly completely bonded to $\mathrm{Pd}$. The trend is similar for the $\mathrm{C} 2-\mathrm{H} 1$ distances in the $\mathrm{Pd}$ bound alkoxide. The bond length of $\mathrm{C} 2-\mathrm{H} 1$ is $1.10 \AA$ in the ground state $\mathbf{2 C}$, while the corresponding distance in $2 \mathrm{D}$ is $3.01 \AA$. The bond distance of $1.97 \AA$ in the transition state indicates the hydrogen-carbon bond is nearly cleaved. The KIE was determined from the difference in the calculated free energies of the transition state. The theoretically determined KIE value is 3.8. ${ }^{46}$ This large value is reasonably consistent with our experimentally determined KIE value of $5.5 \pm 0.1$, indicating our model is relevant with the caveat that error values in these calculations are difficult to estimate.

Further examination of the computational models reveals finer detail of this $\beta$-hydride elimination. The computational studies depict the acetate counterion in the Pd square plane weakly chelating the carbonyl oxygen in $\mathbf{2 C}$ (Figure 8). Transition state model $\mathbf{2} \mathbf{C}^{\ddagger}$ shows the acetate counterion rotated out of plane during $\beta$-hydride elimination. This change from the ground state to the transition state is supported experimentally by comparison of the activation parameters at $50{ }^{\circ} \mathrm{C}$ for the oxidations of sec-phenethyl alcohol, benzyl alcohol, and 2-decanol (Figure 9, Table 2). Interestingly, benzyl alcohol and 2-decanol have positive $\Delta S^{\ddagger}$ values, while the $\Delta S^{\ddagger}$ for sec-phenethyl alcohol is close to unity. The positive values indicate there is less organization in the transition state than in the ground state. This is consistent with the computational model with a gain in rotational degrees of freedom when acetate is rotated out of plane in the transition state compared to the ground state, where the acetate is chelated in the square plane of Pd. It is important to note that the experimental $\Delta G^{\ddagger}$ of $21.2 \pm 0.7$ at $50^{\circ}$ C correlates well with the calculated $\Delta G^{\ddagger}$ of $22.6 \mathrm{kcal} / \mathrm{mol}$.

\section{Alternative Scenarios for a Large KIE Value}

The experimental data and literature precedent thus far point toward rate-limiting $\beta$-hydride elimination. However, alternative scenarios should be considered that may account for the large KIE. One possibility involves direct $\beta$-hydride elimination to the acetate counterion to form $\operatorname{Pd}(0)$, acetic acid, and ketone product through a possible linear transition state (Scheme 3). APT charge calculations on each atom of $\mathbf{2 C}$ indicate $\mathrm{O}(3)$ and $\mathrm{O}(2)$ to be electron rich. ${ }^{47}$ These calculations indicate hydride nucleophilic attack on either acetate oxygen is highly unlikely. In fact, all attempts to optimize a direct transition state failed, with the acetate oxygen strongly repulsing the hydride. Experimental evidence considering the electronics of different carboxylates (vide infra) further contradicts this proposal.

Another possibility could be that reductive elimination is rate limiting, where a large KIE could be observed through a linear-type transition state. A linear transition state could only occur through an intermolecular deprotonation of the hydride. While this type of process cannot be completely ruled out, the concentration of exogenous base (acetate) is very low under the acidic reaction conditions, which renders this an unlikely alternative. In this case, a highly organized transition state would be predicted, leading to a large negative $\Delta S^{\ddagger}$, which is not observed. Additionally, under acidic conditions, reductive elimination has been shown to be reversible, which leads to insignificance in the measurement of a KIE. ${ }^{48}$ Although this circumstantial evidence does point toward rate-limiting $\beta$-hydride elimination, it is impossible to rule out a scenario where the large KIE value is derived from the combination of reversible $\beta$-hydride elimination (an equilibrium isotope effect) and rate-limiting reductive elimination (a primary KIE).

\section{Roles of Acetic Acid}

While the initial goal of the catalyst design was to avoid additives, it was found empirically that additive acetic acid was mandatory for consistent oxidation reactions. However, the selection of acetic acid as an additive in the optimization process was based on the proposed 
mechanism where acetic acid is a byproduct or functional reagent in several steps. Additionally, by increasing the amount of acetic acid in the reaction, air can be substituted for pure $\mathrm{O}_{2}$, showcasing the ability of acetic acid to modulate the catalysis. Therefore, identifying the role (s) of acetic acid should provide insight into the robust features of this catalyst system.

Considering the initial kinetic evidence strongly suggests rate-limiting $\beta$-hydride elimination, a predicted role of additive acetic acid is reprotonation of the palladium alkoxide, thus inhibiting the alcohol oxidation and decreasing the oxidation rates. A simplified rate equation describing this kinetic scenario shows the rate should have an inverse first-order dependence on acetic acid concentration (eq 2). To determine whether acetic acid

$$
\text { rate }=\frac{k_{\mathrm{obs}}[\mathbf{1}][\mathbf{2}]}{[\mathrm{HOAc}]}
$$

simply inhibits alcohol oxidation or has a more profound role within the catalytic system, the dependence of oxidation rate on acetic acid concentration was evaluated from 0 to $67.5 \mathrm{mM}$ (from 0 to $15 \mathrm{~mol} \%$ ). Interestingly, an initial rate increase was observed at low concentrations of additive acetic acid (Figure 10). A maximal rate was achieved at $2.79 \mathrm{mM}(0.62 \mathrm{~mol} \%)$ acetic acid followed by inhibition as more acetic acid was added. When the data ranging from 6.75 to $67.5 \mathrm{mM}$ (from 1.5 to $15 \mathrm{~mol} \%$ ) were fit to a simple inverse first-order equation using nonlinear least-squares analysis, the agreement was excellent (Figure 11). The results under these conditions are consistent with a simple rate equation similar to eq 2 . However, the observations from 0 to $1.5 \mathrm{~mol} \%$ allude to a more complicated scenario with acetic acid playing multiple roles within the catalytic system.

To understand how acetic acid enhances the rates of alcohol oxidation under low concentrations, the rates of alcohol disappearance were examined at different HOAc concentrations (Figure 12). Analysis of these data using a pseudo-first-order plot showed distinct linearity for the reactions carried out with 2 and 3 mol \% HOAc. This confirms the first-order rate dependence on $s e c$-phenethyl alcohol concentration and the relative simplicity of the oxidation when $>2 \mathrm{~mol} \% \mathrm{HOAc}$ is added. The plots also show the relative retardation of oxidation rate by adding $3 \mathrm{~mol} \%$ HOAc compared to 2 mol \% HOAc predicted by eq 2 . However, analysis of the data for the reactions run at 0 and $0.75 \mathrm{~mol} \% \mathrm{HOAc}$ shows a significant deviation from linearity. The oxidation at $0 \mathrm{~mol} \% \mathrm{HOAc}$ did not proceed to completion, while the reaction at $0.75 \mathrm{~mol} \%$ had a much greater intial oxidation rate and overall conversion of alcohol, demonstrating that low concentrations of additive HOAc increase oxidation rates. These data support a time-dependent process, presumably a catalyst decomposition pathway, is occurring at low acid concentration.

Previous studies indicate Pd-catalyzed oxidation of alcohols involves generation of $\operatorname{Pd}(0)$ species which are oxidized by molecular oxygen. ${ }^{49}$ A proposed pathway of catalyst decomposition is the aggregation of $\mathrm{Pd}(0)$ species to form inactive $\mathrm{Pd} .{ }^{50}$ Additive acetic acid can decrease catalyst decomposition by retarding the rate of alcohol oxidation through reprotonation of $\mathbf{C}$, thus preventing the buildup of $\operatorname{Pd}(0)$ species. This alcohol oxidation rate retardation was clearly demonstrated in Figure 11 from 6.75 to $67.5 \mathrm{mM}$ (from 1.5 to $15 \mathrm{~mol}$ $\%$ ) acetic acid. The assumption of catalyst decomposition with no additive acetic acid suggests that a step involved in Pd(II) catalyst regeneration also influences the rate. By adding acetic acid, $\operatorname{Pd}(0)$ concentration can be decreased with concomitant slowing of the decomposition rate through two possible turnover steps. With rate-limiting oxygenation, oxidative addition of acetic acid to $\operatorname{Pd}(0)$ species can re-form palladium hydride $\mathbf{D} .^{48}$ Additive acetic acid can also accelerate the protonation of palladium peroxo $\mathbf{F}$, preventing formation of $\operatorname{Pd}(0)$ through reversible oxygenation. 
To probe these possible scenarios, the rate dependence on sec-phenethyl alcohol concentration was evaluated by measuring initial rates with no additive acetic acid. A log-log plot was constructed (Figure 13), and a partial order of $0.50 \pm 0.02$ was observed, which is consistent with two transition states of comparable free energy. ${ }^{51}$ That is, $\beta$-hydride elimination within the manifold of alcohol oxidation is competitive with the turnover-limiting step of $\mathrm{Pd}$ (II) catalyst regeneration. To further explore this, a KIE value of $1.7 \pm 0.2$ was measured with no additive acetic acid. This value is much smaller than the KIE value measured $(5.5 \pm 0.1)$ when $9 \mathrm{mM}(2 \mathrm{~mol} \%)$ acetic acid is included. Although not large, the KIE value of $1.7 \pm 0.2$ is a significant primary KIE, which implies that $\beta$-hydride elimination influences the rate when no additive acetic acid is present, but the considerable diminishment of the KIE and a partial order dependence on alcohol concentration suggest a step in $\mathrm{Pd}(\mathrm{II})$ catalyst regeneration is competitive. To explore this hypothesis, the KIE values for sec-phenethyl alcohol oxidation were measured at acetic acid concentrations ranging from 0 to $9 \mathrm{mM}$ (from 0 to $2 \mathrm{~mol} \%$ ) (Table 3). The KIE values gradually increase as the concentration of additive acetic acid is increased. This is consistent with a change in rate-influencing steps from a combination of $\beta$ hydride elimination and a turnover-limiting step to only $\beta$-hydride elimination at $9 \mathrm{mM}$ ( $2 \mathrm{~mol}$ $\%)$ acetic acid.

The two scenarios in which a turnover-limiting step can influence Pd catalyst decomposition are (1) turnover-limiting oxygenation with reversible reductive elimination and/or (2) reversible oxygenation with protonation of palladium peroxo $\mathbf{F}$ to form $\mathbf{A}$ and evolution of $\mathrm{H}_{2} \mathrm{O}_{2}$ (Scheme 4). If oxygenation $\left(k_{5}[\mathbf{E}]\left[\mathrm{O}_{2}\right]\right)$ is turnover limiting at $0 \mathrm{mM} \mathrm{HOAc}$, a rate dependence on molecular oxygen concentration should be observed. The alcohol oxidation rate dependence on percent molecular oxygen was measured from 0 to $100 \%$ (molecular oxygen and nitrogen mixtures) at balloon pressure. ${ }^{52}$ At 0 mol $\%$ acetic acid, a zeroth-order rate dependence is observed from $29 \%$ to $100 \% \mathrm{O}_{2} / \mathrm{N}_{2}$ (Figure 14). However, significant decomposition was noted immediately upon alcohol addition at $23 \% \mathrm{O}_{2} / \mathrm{N}_{2}$. These results indicate oxygenation is not turnover limiting under these conditions, but a minimal concentration of oxygen must be present for Pd(II) catalyst regeneration. This also is congruent with being unable to effectively oxidize alcohols using air under these conditions. Additionally, oxygen dependence was evaluated at 3 and $7 \mathrm{~mol} \%$ (13.5 and $31.5 \mathrm{mM}$ ) HOAc from 5\% to $100 \% \mathrm{O}_{2} / \mathrm{N}_{2}$. At $3 \mathrm{~mol} \%$ acetic acid, there is no dependence on oxygen concentration from $23 \%$ to $100 \% \mathrm{O}_{2} / \mathrm{N}_{2}$. From $5 \%$ to $23 \% \mathrm{O}_{2} / \mathrm{N}_{2}$, significant decomposition is observed. At a higher acetic acid concentration, $7 \mathrm{~mol} \%$, the rate dependence is zeroth order in oxygen concentration from 5\% to 100\% oxygen with no observed decomposition. These observations demonstrate how air can be used as an effective $\mathrm{O}_{2}$ source by using increased concentrations of acetic acid. From 0 to $7 \mathrm{~mol} \%$ acetic acid, decomposition occurs at progressively lower percentages of oxygen until it is not detected at $7 \mathrm{~mol} \% \mathrm{HOAc}$. It is important to note that this phenomenon corresponds to a significant decrease in alcohol oxidation rate due to inhibition through reprotonation $\left(\mathbf{C}\right.$ to $\mathbf{B}$ ), which regulates the concentration of $\mathrm{O}_{2}$ needed for efficient catalyst regeneration.

Competitive turnover-limiting protonation of peroxo $\mathbf{F}$ is most consistent with the above kinetic data and the observation of a partial positive order acetic acid concentration dependence from 0 to $2.79 \mathrm{mM}$ (from 0 to $0.62 \mathrm{~mol} \%$ ). With this proposal, the observation of decomposition at $0 \mathrm{mM}$ acetic acid suggests reversible oxygenation. Therefore, as more acetic acid is added, the rate of protonation of $\mathbf{F}$ increases while the rate of alcohol oxidation decreases from inhibition through reprotonation of $\mathbf{C}$. When $>2 \mathrm{~mol} \%$ acetic acid is added, protonation of $\mathbf{F}$ is fast relative to alcohol oxidation, leading to observed rate-limiting $\beta$-hydride elimination under these conditions. This scenario rationalizes the change in alcohol dependence from partial order at low concentrations of acetic acid to first order at higher concentrations of acetic acid. It is also consistent with the change in KIE values from 1.7 at $0 \mathrm{mM}$ acetic acid when 
there is a combination of rate-influencing steps to 5.5 at $9 \mathrm{mM} \mathrm{(2} \mathrm{mol} \mathrm{\% )} \mathrm{acetic} \mathrm{acid} \mathrm{when}$ only $\beta$-hydride elimination is rate limiting.

Using the King-Altman method, a rate law can be derived to mathematically describe Scheme 4 , where $\beta$-hydride elimination and the protonation of $\mathbf{F}$ are assumed as irreversible (eq 3). ${ }^{52}$, 53

$$
\text { rate }=\frac{k_{1}[2] k_{2} k_{3} k_{4} k_{5}\left[\mathrm{O}_{2}\right] k_{6}[\mathrm{HOAc}]\left[\mathrm{Pd}_{\mathrm{T}}\right]}{k_{6}[\mathrm{HOAc}] k_{\mathrm{prot}}+k_{1}[2] k_{\mathrm{alc}}}
$$

$$
\begin{aligned}
& k_{\text {prot }}= k_{2} k_{3} k_{4} k_{5}\left[\mathrm{O}_{2}\right]+k_{-1} k_{3} k_{4} k_{5}\left[\mathrm{O}_{2}\right]+ \\
& k_{-1} k_{-2}[\mathrm{HOAc}] k_{4} k_{5}\left[\mathrm{O}_{2}\right]+k_{1}[2] k_{3} k_{4} k_{5}\left[\mathrm{O}_{2}\right]+ \\
& k_{-2}[\mathrm{HOAc}] k_{1}[2] k_{4} k_{5}\left[\mathrm{O}_{2}\right]+k_{1}[2]+k_{2} k_{4} k_{5}\left[\mathrm{O}_{2}\right]+ \\
& k_{1}[2] k_{2} k_{3} k_{5}\left[\mathrm{O}_{2}\right]+k_{1}[2] k \\
&{ }_{2} k_{3} k_{-4}[\mathrm{HOAc}]+k_{1}[2] k_{2} k_{3} k_{4}
\end{aligned}
$$

$$
k_{\mathrm{alc}}=\left(k_{2} k_{3} k_{-4}[\mathrm{HOAc}] k_{-5}+k_{2} k_{3} k_{4} k_{-5}+k_{2} k_{3} k_{4} k_{5}\left[\mathrm{O}_{2}\right]\right)
$$

In eq $3, k_{\text {prot }}$ is all terms in the denominator that $k_{6}[\mathrm{AcOH}]$ can be factored from, $k_{\text {alc }}$ is the remaining terms in the denominator with $k_{1}[2]$ factored out, and $\left[\mathbf{P d}_{\mathbf{T}}\right]$ is the total concentration of all Pd species. When no acetic acid is added, the full derived rate law describes the kinetic events. The terms in the denominator, $k_{6}[\mathrm{AcOH}] k_{\text {prot }}$ and $k_{1}[2] k_{\text {alc }}$, must be comparable because of the observation of a partial order dependence on alcohol concentration and a partial order dependence on acetic acid concentration. As more acetic acid is added to the reaction, the magnitude of $k_{6}[\mathrm{AcOH}] k_{\text {prot }}$ increases dramatically compared to that of $k_{1}[2] k_{\mathrm{alc}}$. Therefore, $k_{6}[\mathrm{AcOH}] k_{\text {prot }}$ completely governs over the other terms in the denominator at higher [HOAc], leading to a simplification of the rate law (eq 4). Two observations allow for further simplification to eq 5: There is no dependence on oxygen concentration, and the rate is limited by $\beta$-hydride elimination at high [HOAc]. This equation describes rate-limiting $\beta$-hydride elimination in the steady-state form. If equilibrium conditions are assumed, the rate simplifies to eq 2 .

$$
\begin{gathered}
\text { rate }=\frac{k_{1}[2] k_{2} k_{3} k_{4} k_{5}\left[\mathrm{O}_{2}\right]\left[\mathrm{Pd}_{\mathrm{T}}\right]}{k_{\text {prot }}} \\
\text { rate }=\frac{k_{1}[2] k_{2} k_{3}\left[\mathrm{Pd}_{\mathrm{T}}\right]}{k_{2} k_{3}+k_{-1} k_{3}+k_{-1} k_{-2}[\mathrm{HOAc}]}
\end{gathered}
$$

\section{$\mathrm{p} K_{\mathrm{a}}$ Dependence}

Considering the significance of acetic acid in $\mathrm{Pd}(\mathrm{I} i \mathrm{Pr})(\mathrm{OAc})_{2}\left(\mathrm{H}_{2} \mathrm{O}\right)$-catalyzed oxidation of alcohols, it is logical that a $\mathrm{p} K_{\mathrm{a}}$ effect could be observed when the carboxylate ligand and additive carboxylic acid are changed. Several catalysts were synthesized by submitting Pd (IiPr) $\mathrm{Cl}_{2}$ dimer complex to salt metathesis with different silver carboxylates. These new Pd (IiPr)(carboxylate) $)_{2}$ complexes were tested for catalytic activity with a 2 mol \% concentration of the corresponding carboxylic acid (eq 6). A Brønsted-type plot was constructed by comparing the measured initial oxidation rates to the $\mathrm{p} K_{\mathrm{a}}$ of the corresponding carboxylic acid 
in $\mathrm{H}_{2} \mathrm{O}$ (Figure 15). ${ }^{54,55}$ A linear free energy relationship was observed with a calculated $\alpha$ value of $1.44 \pm 0.13$. An $\alpha$ value of $1.44 \pm 0.13$ is very large, indicating a significant $\mathrm{p} K_{\mathrm{a}}$ effect. By definition, $\alpha$ values should not exceed 1.00 if describing only one step. Since the anionic ligand was changed as well as the added acid, two influences are manifested in this $\alpha$ value: the basicity of the anionic ligand/base for deprotonation of Pd-bound alcohol $\mathbf{B}$ and the acidity of the acid for reprotonation of palladium alkoxide $\mathbf{C}$. With such a large $\alpha$ value, reprotonation is probably the dominant step, with a weaker carboxylic acid leading to higher alcohol oxidation rates. ${ }^{56}$
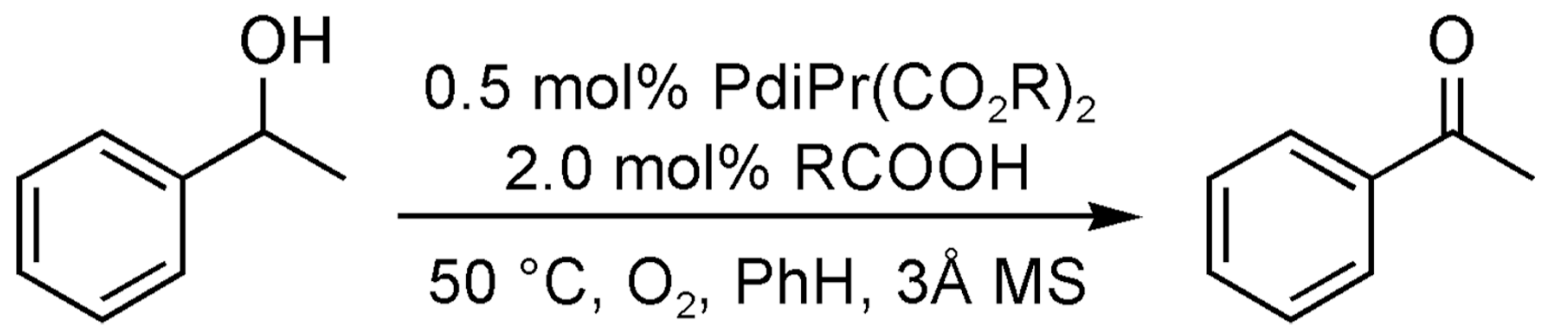

To differentiate the influence of carboxylate/carboxylic acid $\mathrm{p} K_{\mathrm{a}}$ on deprotonation of $\mathbf{B}$ and on reprotonation of $\mathbf{C}$, the $\mathrm{Pd}(\mathrm{I} i \mathrm{Pr})$ (carboxylate) ${ }_{2}$ complexes were assessed with no additive carboxylic acid, where reprotonation of $\mathbf{C}$ should be negligible. ${ }^{52}$ However, performing these experiments at $0 \mathrm{~mol} \%$ acetic acid conditions changes the scenario of rate-limiting steps. Under these conditions, previous experimental observations show turnover-limiting protonation of $\mathbf{F}$ is competitive with $\beta$-hydride elimination. Therefore, the acid/base effects most likely being evaluated under these conditions are deprotonation of Pd-bound alcohol $\mathbf{B}$ by carboxylate and protonation of peroxo $\mathbf{F}$ by carboxylic acid. A carboxylate from a higher $\mathrm{p} K_{\mathrm{a}}$ carboxylic acid provides for a better base for deprotonation of $\mathbf{B}$. In contrast, a carboxylic acid with a lower $\mathrm{p} K_{\mathrm{a}}$ facilitates protonation of peroxo $\mathbf{F}$. A positive linear free energy relationship was observed with a calculated $\alpha$ value of $0.31 \pm 0.04$ (Figure 16). This value is significantly smaller than the value of $1.44 \pm 0.13$ at $2 \mathrm{~mol} \%$ carboxylic acid conditions and within the typical range from 0 to 1.00 . The positive slope indicates a stronger conjugate base facilitates the overall reaction. This corresponds with deprotonation of the Pd-bound alcohol being more sensitive to $\mathrm{p} K_{\mathrm{a}}$ effects than protonation of peroxo $\mathbf{F}$ with no added acid. These results showcase the importance of the basicity of the carboxylate ligands for an efficient Pd catalyst for oxidation of alcohols.

Of note is the $\log \left(k_{\mathrm{obs}}\right)$ value for $\mathrm{Pd}(\mathrm{I} i \mathrm{Pr})(\text { pivalate })_{2}$ has a standard residual value of 1.6. Pivalate was the largest counterion tested in this experiment. Relief of steric strain through formation of the alkoxide as well as the higher basicity of pivalate provides an explanation for the increased catalytic activity relative to those of other carboxylate catalysts. These studies have led to the development of a highly active $\operatorname{Pd}(\mathrm{I} i \operatorname{Pr})(\text { pivalate })_{2}$ catalyst for oxidation of alcohols at room temperature using air, which will be reported in due course. ${ }^{57}$

\section{Overall Mechanistic Implications}

The details for the aerobic oxidation of alcohols with $\operatorname{Pd}(\mathrm{IiPr})(\mathrm{OAc})_{2}\left(\mathrm{H}_{2} \mathrm{O}\right)$ have been elucidated, confirming much of the mechanistic rationale used to design it. Using a monodentate dative ligand and an anionic ligand as an internal base yields a highly effective catalyst system for alcohol oxidation. Initially, kinetic experiments revealed a relatively simple system, but as the alcohol oxidation was evaluated at other conditions, it became clear the entire 
scenario is much more complicated. Two results highlight the unique nature of the catalytic system: a large KIE value and the dynamic dependence on [HOAc].

The observed large KIE value leads to a proposed late transition state with significant $\mathrm{Pd}-\mathrm{H}$ character. Theoretical studies support this late-transition-state model for $\beta$-hydride elimination from the $\mathrm{Pd}(\mathrm{Ii} \mathrm{Pr})(\mathrm{OAc})$ alkoxide, and the calculated KIE value of 3.8 correlates with the experimentally determined KIE value of $5.5 \pm 0.1$. As demonstrated by large differences in KIE and $\rho$ values, the nature of the ligand has a significant influence on $\beta$-hydride elimination. A single monodentate ligand provides an open coordination site leading to the proposed late transition state, while a bidentate ligand (or two monodentate ligands) most likely involves a 5 -coordinate early transition state. These results reveal the ability to modulate $\beta$-hydride elimination by careful selection of ligand and lead to significant implications in the design of asymmetric catalysts.

Acetic acid plays multiple roles in aerobic oxidation of alcohols with $\mathrm{Pd}(\mathrm{Ii} \operatorname{Pr})(\mathrm{OAc})_{2}\left(\mathrm{H}_{2} \mathrm{O}\right)$. Acetic acid is vital to the system to prevent decomposition of the catalyst and maintain consistent reactions. A key observation is increasing acetic acid concentration modulates the steps that influence the alcohol oxidation and Pd catalyst regeneration rates. When no acetic acid is present, $\beta$-hydride elimination works synergistically with turnover-limiting protonation to influence the overall reaction rate. Addition of acetic acid increases the rate of protonation of $\mathbf{F}$ until it is no longer rate influencing, rendering $\beta$-hydride elimination the single ratecontrolling step. The discovery of Pd catalyst decomposition when protonation of the peroxo species $\mathbf{F}$ influences the overall rate suggests oxygenation is reversible, allowing for a decomposition pathway through $\mathrm{Pd}(0)$. Key studies of rate dependence on oxygen percent reveal additive acetic acid decreases alcohol oxidation rates and prevents deoxygenation through reversible peroxo formation. This ability to balance alcohol oxidation with Pd catalyst regeneration events allows for the use of air as a viable oxygen source.

The balance of alcohol oxidation and Pd catalyst regeneration events with additive acetic acid has allowed for insight into both realms of the catalytic cycle. This insight allows for the analysis of other mechanistic pathways for regeneration. It has been proposed for Pd-catalyzed aerobic alcohol oxidations that a palladium hydroperoxide species can be converted directly to the palladium alkoxide by alcohol especially under basic conditions. ${ }^{3,11 \mathrm{a}}$ The need of acetic acid for efficient catalyst turnover implies a Pd(II) species such as $\mathbf{A}$ is formed. This can bind the alcohol as a Lewis acid to increase the acidity of the hydroxyl proton, allowing for effective deprotonation and formation of palladium alkoxide $\mathbf{B}$. If the palladium peroxo $\mathbf{F}$ can be converted directly to $\mathbf{B}$ when exposed to alcohol in the presence of base, addition of $\mathrm{NBu}_{4} \mathrm{OAc}$ should promote turnover of the Pd catalyst and prevent decomposition. Instead, significant decomposition is observed with addition of $\mathrm{NBu}_{4} \mathrm{OAc}$ to the extent that initial rates can only be measured to $3 \mathrm{~mol} \% \mathrm{NBu}_{4} \mathrm{OAc}$ in the oxidation of sec-phenethyl alcohol. ${ }^{52}$ These observations contradict base-promoted turnover of the palladium peroxo species directly to the palladium alkoxide $\mathbf{C}$, but strongly support the regeneration of $\mathbf{A}$, followed by substrate binding and subsequent deprotonation to $\mathbf{C}$.

\section{Conclusions}

The development of a well-defined catalyst, $\mathrm{Pd}(\mathrm{Ii} \mathrm{Pr})(\mathrm{OAc})_{2}\left(\mathrm{H}_{2} \mathrm{O}\right)$, represents a clear example where catalyst design was significantly enhanced by detailed structural and kinetic information. The study of this catalyst has led to a fascinating picture of $\beta$-hydride elimination and how it can be modulated by careful selection of ligand and counterion. For other Pd-catalyzed aerobic oxidations of alcohols, only one realm of the catalytic cycle has been studied kinetically. Elucidation of the roles of acetic acid allowed for the concomitant study of Pd-catalyzed alcohol oxidation and catalyst regeneration by molecular oxygen. Further studies are aimed at 
understanding the precise mechanism of decomposition and using these studies as a foundation to design new catalysts for other Pd-catalyzed aerobic oxidations.

\section{Acknowledgment}

This work was supported by the National Institutes of Health (NIGMS Grant No. RO1 GM63540) and supported by a Research Innovation Award sponsored by Research Corp. We thank the University of Utah Research Foundation, Merck Research, Rohm and Haas Research, and Invenux Inc. for partial support of this research. We thank the donors of the Petroleum Research Fund, administered by the American Chemical Society, for partial support of this research (PRF Grant No. 37536-G1). We thank Johnson Matthey for supplies of various palladium salts. The X-ray crystal structure analysis was performed by Atta Arif. We also thank David R. Jensen and Professor Thanh N. Truong for insightful discussions.

\section{References}

1. Berzelius J. J. Ann. Phys. Chem 1828;13:435-488.

2. (a) Moreno-Manas M, Pleixats R, Villarroya S. Organometallics 2001;20:4524-4528. (b) Bellosta V, Benhaddou R, Czernecki S. Synlett 1993:861-863. (c) Benhaddou R, Czernecki S, Ville G, Zegar A. Organometallics 1988;7:2435-2439. (d) Zaw K, Lautens M, Henry PM. Organometallics 1983;2:197199. (e) Tomioka H, Takai K, Oshina K, Nozaki H. Tetrahedron Lett 1981;22:1605-1608.

3. For a recent review on Pd-catalyzed oxidations of alcohols, see: Muzart J. Tetrahedron 2003;59:57895816.5816

4. Nikiforova AV, Moiseev II, Syrkin YK. Zh. Obshch. Khim 1964;33:3239-3242.

5. Lloyd WG. J. Org. Chem 1967;32:2816-2819.

6. Blackburn TF, Schwartz JJ. Chem. Commun 1977:157-158.

7. Peterson KP, Larock RC. J. Org. Chem 1998;63:3185-3189.

8. This oxidative system has been extended to several transformations. For intramolecular cyclizations, heterocyclizations, and carbocylizations, see: (a)Toyota M, Sasaki M, Ihara M. Org. Lett 2003;5:11931195.1195 [PubMed: 12688717] (b)Toyota M, Rudyanto M, Ihara M. J. Org. Chem 2002;67:33743386.3386 [PubMed: 12003549] (c)Toyota M, Ihara M. Synlett 2002:1211-1222.1222 (d)Toyota M, Ilangovan A, Okamoto R, Masaki T, Arakawa M, Ihara M. Org. Lett 2002;4:4293-4296.4296 [PubMed: 12443081] (e)Toyota M, Odashima T, Wada T, Ihara M. J. Am. Chem. Soc 2000;122:90369037.9037 (f)Toyota M, Rudyanto M, Ihara M. Tetrahedron Lett 2000;41:8929-8932.8932 (g)Toyota M, Wada T, Ihara M. J. Org. Chem 2000;65:4565-4570.4570 [PubMed: 10959860] (h)Toyota M, Wada T, Fukumoto K, Ihara M. J. Am. Chem. Soc 1998;120:4916-4925.4925 (i)Larock RC, Hightower TR. Synlett 1998:522-524.524 (j)Rönn M, Andersson PG, Bäckvall J-E. Tetrahedron Lett 1997;38:3603-3606.3606 (k)Rönn M, Andersson PG, Bäckvall J-E. Acta Chem. Scand 1997;51:773777.777 (1)Larock RC, Hightower TR, Hasvold LA, Peterson KP. J. Org. Chem 1996;61:35843585.3585 [PubMed: 11667199] (m)Rönn M, Bäckvall J-E, Andersson PG. Tetrahedron Lett 1995;36:7749-7752.7752 (n)van Bentham RATM, Hiemstra H, van Leeuwen PWNM, Geus JW, Speckamp WN. Angew. Chem., Int. Ed. Engl 1995;34:457-460.460 (o)van Bentham RATM, Hiemstra H, Longarela GR, Speckamp WN. Tetrahedron Lett 1994;35:9281-9284.9284 (p)van Bentham RATM, Hiemstra H, Michels JJ, Speckamp WN. J. Chem. Soc., Chem. Commun 1994:357-359.359 (q)Larock RC, Hightower TR. J. Org. Chem 1993;58:5298-5300.5300

9. For dehydrosilylation of silyl enol ethers using $\mathrm{Pd}(\mathrm{II}) / \mathrm{O}_{2}$ in DMSO, see: Larock RC, Hightower TR, Kraus GA, Hahn P, Zheng D. Tetrahedron Lett 1995;36:2423-2426.2426

10. For oxidative $\mathrm{C}-\mathrm{C}$ bond cleavage of tertiary alcohols using $\mathrm{Pd}(\mathrm{II}) / \mathrm{O}_{2}$ in DMSO, see: Park S-B, Cha JK. Org. Lett 2000;2:147-149.149 [PubMed: 10814268]

11. (a) Nishimura T, Onoue T, Ohe K, Uemura S. J. Org. Chem 1999;64:6750-6755. [PubMed: 11674682] (b) Nishimura T, Onoue T, Ohe K, Uemura S. Tetrahedron Lett 1998;39:6011-6014.

12. For a review, see: Nishimura T, Ohe K, Uemura S. Synlett 2004;2:201-216.216

13. For ring opening of hydroxycyclopropanes, see: Park S-B, Cha JK. Org. Lett 2000;2:147-149.149 [PubMed: 10814268]

14. For intramolecular oxidative amination, see: Fix SR, Brice JL, Stahl SS. Angew. Chem., Int. Ed 2002;41:164-166.166 
15. For a Wacker cyclization, see: Trend RN, Ramtohul EM, Ferreira EM, Stoltz BM. Angew. Chem., Int. Ed 2003;42:2892-2895.2895

16. For annulation of indoles, see: Ferreira EM, Stoltz BM. J. Am. Chem. Soc 2003;125:9578-9579.9579 [PubMed: 12904010]

17. (a) ten Brink G-J, Arends IWCE, Hoogenraad M, Verspui G, Sheldon RA. Adv. Synth. Catal 2003;345:497-505. (b) ten Brink G-J, Arends IWCE, Sheldon RA. Adv. Synth. Catal 2002;344:355369. (c) Sheldon RA, Arends IWCE, ten-Brink G-J, Dijksman A. Acc. Chem. Res 2002;35:774-781. [PubMed: 12234207] (d) ten Brink G-J, Arends IWCE, Sheldon RA. Science 2000;287:1636-1639. [PubMed: 10698735]

18. Hallman K, Moberg C. Adv. Synth. Catal 2001;343:260-263.For a related catalyst, see: Paavola S, Zetterberg K, Privalov T, Csöregh I, Moberg C. Adv. Synth. Catal 2004;346:237-244.244

19. Heterogeneous and biphasic Pd catalyst systems have been reported to oxidize alcohols under air atmosphere, see: (a)Gómez-Bengoa E, Noheda P, Echavarren AM. Tetrahedron Lett 1994;35:70977098.7098 (b)Aït-Mohand S, Hénin F, Muzart J. Tetrahedron Lett 1995;36:2473-2476.2476

20. Schultz MJ, Park CC, Sigman MS. Chem. Commun 2002:3034-3035.

21. For the use of catalytic Pd(II) and $\mathrm{NEt}_{3}$ in oxidative amination, see: Timokhin VI, Anastasi NR, Stahl Shannon S. J. Am. Chem. Soc 2003;125:12996-12997.12997 [PubMed: 14570451]

22. Steinhoff BA, Fix SR, Stahl SS. J. Am. Chem. Soc 2002;124:766-767. [PubMed: 11817948]

23. Steinhoff BA, Stahl SS. Org. Lett 2002;4:4179-4181. [PubMed: 12423116]

24. For mechanistic studies and elucidation of the role of base in $\operatorname{Pd}[(-)$ sparteine $] \mathrm{Cl}_{2}$-catalyzed oxidative kinetic resolution of secondary alcohols, see: Mandal SK, Sigman MS. J. Org. Chem 2003;68:75357537.7537 [PubMed: 12968915] (b) Mueller JA, Sigman MS. J. Am. Chem. Soc 2003;125:70057013. [PubMed: 12783555] (c) Mueller JA, Jensen DR, Sigman MS. J. Am. Chem. Soc 2002;124:8202-8203. [PubMed: 12105896] (d) Jensen DR, Pugsley JS, Sigman MS. J. Am. Chem. Soc 2001;123:7475-7476. [PubMed: 11472200]Simultaneously and independently a related kinetic resolution was reported, see: Ferreira EM, Stoltz BM. J. Am. Chem. Soc 2001;123:7725-7726.7726 [PubMed: 11481006] (f) Bagdanoff JT, Ferreira EM, Stoltz BM. Org. Lett 2003;5:835-837. [PubMed: 12633084] (g) Bagdanoff JT, Stoltz BM. Angew. Chem., Int. Ed 2004;43:353-357.

25. For a review, see: Herrmann WA. Angew. Chem., Int. Ed 2002;41:1290-1309.1309

26. Jensen DR, Sigman MS. Org. Lett 2003;5:63-65. [PubMed: 12509891]

27. Jensen DR, Schultz MJ, Mueller JA, Sigman MS. Angew. Chem., Int. Ed 2003;42:3810-3813.

28. The sec-phenethyl alcohol concentration was decreased to $0.45 \mathrm{M}$, with the relative mole percentages of all other reagents remaining the same These reactions were performed at $50 \pm 0.1^{\circ} \mathrm{C}$ in benzene, see: See the Supporting Information for details.

29. Determined by measurement of the initial oxidation rate of sec-phenethyl alcohol with $0-1 \mathrm{~mol} \%$ $\mathrm{Pd}(\mathrm{Ii} \mathrm{Pr})(\mathrm{OAc})_{2}\left(\mathrm{H}_{2} \mathrm{O}\right)$.

30. $\sigma$ values were obtained from Lowry TH, Richardson KS. Mechanism and Theory in Organic Chemistry (3rd ed.) 19873rd ed. New YorkHarper and Row:144.

31. For a discussion on the magnitude of kinetic isotope effects, see: Westheimer FH. Chem. Rev 1961;61:265-273.273

32. Other scenarios have been reported where reactions with nonlinear transition states give high KIE values. The high KIE values were attributed to significant intermolecular force constants. For discussion of this concept, see: Motell EL, Boone AW, Fink WH. Tetrahedron 1978;34:16191626.1626 Additionally, for discussion of proton-transfer reactions and KIE, see: O'Ferrall RAM. Caldin EF, Gould V. Chapter 8. Proton-Transfer Reactions. 1975NewYorkChapman \& Hall

33. Collins, CJ.; Bowman, NS. Isotope Effects in Chemical Reactions. New York: Van Nostrand Reinhold Co; 1970.

34. Andrews L, Wang X, Alikhani ME, Manceron L. J. Phys. Chem. A 2001;105:3052-3063.

35. A similar proposal was recently reported, see: Trend RM, Stoltz BM. J. Am. Chem. Soc 2004;126:4482-4483.4483 [PubMed: 15070342] While the current paper was in review, a computational model of the $\mathrm{Pd}(\mathrm{II})$-catalyzed oxidative kinetic resolution of secondary alcohols using $(-)$-sparteine was reported. In this study, the authors report that the chloride ion is closely associated with the Pd(II) center (3.0 $)$ at the transition state for $\beta$-hydride elimination, see: Nielsen RJ, Keith JM, Stoltz BM, Goddard WA III. J. Am. Chem. Soc 2004;126:7967-7974.7974 [PubMed: 15212546] 
36. Initial calculations performed on both cis- and trans-Pd(IiPr)(OAc) alkoxides (the NHC ligand was truncated) revealed the Pd complex with the alkoxide cis to the carbene ligand was found to be significantly lower in energy than the trans geometric isomer. See the Supporting Information for details.

37. Frisch, MJ.; Trucks, GW.; Schlegel, HB.; Scuseria, GE.; Robb, MA.; Cheeseman, JR.; Zakrzewski, VG.; Montgomery, JA.; Kudin, KN.; Burant, JC.; Millam, JM.; Stratmann, RE.; Tomasi, J.; Barone, V.; Mennucci, B.; Cossi, M.; Scalmani, G.; Rega, N.; Iyengar, S.; Petersson, GA.; Ehara, M.; Toyota, K.; Nakatsuji, H.; Adamo, C.; Jaramillo, J.; Cammi, R.; Pomelli, C.; Ochterski, J.; Ayala, PY.; Morokuma, K.; Salvador, P.; Dannenberg, JJ.; Dapprich, S.; Daniels, AD.; Strain, MC.; Farkas, O.; Malick, DK.; Rabuck, AD.; Raghavachari, K.; Foresman, JB.; Ortiz, JV.; Cui, Q.; Baboul, AG.; Clifford, S.; Cioslowski, J.; Stefanov, BB.; Liu, G.; Liashenko, A.; Piskorz, P.; Komaromi, I.; Gomperts, R.; Martin, RL.; Fox, T.; Keith, DJ.; Al-Laham, MA.; Peng, CY.; Nanayakkara, A.; Challacombe, M.; Gill, PMW.; Johnson, B.; Chen, W.; Wong, MW.; Andres, JL.; Gonzalez, C.; Head-Gordon, M.; Replogle, ES.; Pople, JA. Gaussian 01. Pittsburgh, PA: Gaussian, Inc; 2001. Development Version (Revision B.01)

38. (a) Becke AD. J. Chem. Phys 1993;98:5648-5652. (b) Becke AD. J. Chem. Phys 1993;98:13721377. (c) Becke AD. Phys. Rev. A 1988;38:3098-3100. [PubMed: 9900728]

39. (a) Miehlich B, Savin A, Stoll H, Preuss H. Chem. Phys. Lett 1989;157:200-206. (b) Lee C, Yang W, Parr RG. Phys. Rev. B 1988;37:785-789.

40. (a) Hay PJ, Wadt WR. J. Chem. Phys 1985;82:270-283. (b) Wadt WR, Hay PJ. J. Chem. Phys 1985;82:284-298. (c) Hay PJ, Wadt WR. J. Chem. Phys 1985;82:299-310.

41. Dunning, TH., Jr; Hay, PJ. Modern Theoretical Chemistry. Schaefer, HF., III, editor. New York: Plenum; 1976. p. 1-28.

42. (a) Frenking G, Antes I, Boehme M, Dapprich S, Ehlers AW, Jonas V, Neuhaus A, Otto M, Stegmann R, Veldkamp A, Vyboishchikov SF. Rev. Comput. Chem 1996;8:63-143. (b) Cundari TR, Benson MT, Lutz ML, Sommerer SO. Rev. Comput. Chem 1996;8:145-202.

43. (a) Kohn W, Sham LJ. Phys. Rev. A 1965;140:1133-1138. (b) Hohenberg P, Kohn W. Phys. Rev. B 1964;136:864-871.

44. Peng C, Schlegel HB. Isr. J. Chem 1993;33:449-454.

45. No scaling factors were applied to frequency calculations. No solvent corrections were applied.

46. Zhang, Shaowen; Truong, Thanh N. VKLab version 1.0. University of Utah; 2001.

47. Mulliken charges and APT charges were both calculated The APT charges best correlated with a $\beta$ hydride elimination mechanism. Mulliken charges indicated the $\beta-\mathrm{H}$ to be more proton-like; therefore, this analysis was not used.

48. For the reversible formation of palladium(II) hydride species under acidic conditions, see: Amatore C, Jutand A, Meyer G, Carelli I, Chiarotto I. Eur. J. Inorg. Chem 2000:1855-1859.1859

49. Two pathways have been suggested to describe how molecular oxygen re-forms the active Pd catalyst: (1) $\mathrm{O}_{2}$ insertion into the $\mathrm{Pd}-\mathrm{H}$ bond or (2) reductive elimination of $\mathrm{Pd}(\mathrm{X})-\mathrm{H}$ to form a $\mathrm{Pd}(0)$ species which is reoxidized by $\mathrm{O}_{2}$ to form a palladium peroxo species. The latter of these pathways is supported by the isolation of a palladium peroxo-bathocuproin (bc) complex by Stahl and co-workers formed by exposure of $\mathrm{Pd}(0)(\mathrm{bc})$ to molecular oxygen, see: Stahl SS, Thorman JL, Nelson RC, Kozee MA. J. Am. Chem. Soc 2001;123:7188-7189.7189 [PubMed: 11459511] They demonstrated the palladium peroxo-bc species yields $\mathrm{Pd}(\mathrm{OAc})_{2}(\mathrm{bc})$ and hydrogen peroxide when exposed to acetic acid. A related Pd-bathocuproine complex was shown to be an excellent catalyst by Sheldon and coworkers for Pd-catalyzed aerobic oxidation of alcohols in aqueous conditions (see ref 17).

50. For a discussion on the nontriviality of $\operatorname{Pd}(0)$ turnover, see: Tsuji J. Palladium Reagents and Catalysts: Innovations in Organic Synthesis 1995New YorkJohn Wiley and Sons:20. For an example of Pd(0) aggregation to precipitate Pd black in the Wacker oxidation, see: Tang HG, Sherrington DC. J. Catal 1993; 142:540, 551.

51. For recent examples, see: (a)Dewanti AR, Xu Y, Mitra B. Biochemistry 2004;43:1883-1890.1890 [PubMed: 14967029] (b)Dewanti AR, Mitra B. Biochemistry 2003;42:12893-12901.12901 [PubMed: 14596603] (c)Waas WF, Rainey MA, Szafranska AE, Dalby KN. Biochemistry 2003;42:12273-12286.12286 [PubMed: 14567689] (d)Kimura Y, Toyoshima N, Hirakawa N, Okamoto K, Ishijima A. J. Mol. Biol 2003;328:939-950.950 [PubMed: 12729766] (e)Fatin-Rouge N, Blanc S, Leize E, Van Dorsselaer A, Baret P, Pierre J-L, Albrecht-Gary A-M. Inorg. Chem 
2000;39:5771-5778.5778 [PubMed: 11151379] (f)Bebelis S, Zeritis AS, Tiropani C, Neophytides SG. Ind. Eng. Chem. Res 2000;39:4920-4927.4927

52. See the Supporting Information for details.

53. For the King-Altman method, see: Cornish-Bowden A. Principles of Enzyme Kinetics 1976LondonButterworth:38-40.40

54. Isaacs, N. Physical Organic Chemistry. Vol. 2nd ed.. Harlow, U.K: Prentice Hall; 1995. p. 381-384.

55. For $\mathrm{pK}_{\mathrm{a}}$ values in water, see: Lide DR. CRC Handbook of Chemistry and Physics (75th ed.). 199575th ed. Boca Raton, FLCRC Press Inc For the $\mathrm{p} K_{\mathrm{a}}$ value of trifluoroacetic acid, see: Budavari, sMerck Index (12th ed.). 199612th ed. Whitehouse Station, NJMerck \& Co., Inc

56. Another consideration is the change in carboxylate ligand may also affect $\beta$-hydride elimination since this ancillary ligand is bound to palladium alkoxide $C$ during rate-limiting $\beta$-hydride elimination. If the bound carboxylate has a significant effect on $\beta$-hydride elimination, electron-withdrawing groups on the carboxylate should increase the electrophilicity of the Pd(II) center. Thus, carboxylic acids with lower $\mathrm{p} K_{\mathrm{a}}$ values should lead to increases in rate. The Brønsted-type plot at 2 mol \% additive carboxylic acid shows the opposite trend where carboxylate ligands with electron-donating groups show increased reaction rates. Thus, the influence of different carboxylate ligands on $\beta$-hydride elimination is probably minimal compared to the acid/base effects present.

57. Hamilton S, Schultz MJ, Sigman MS. Unpublished results. 


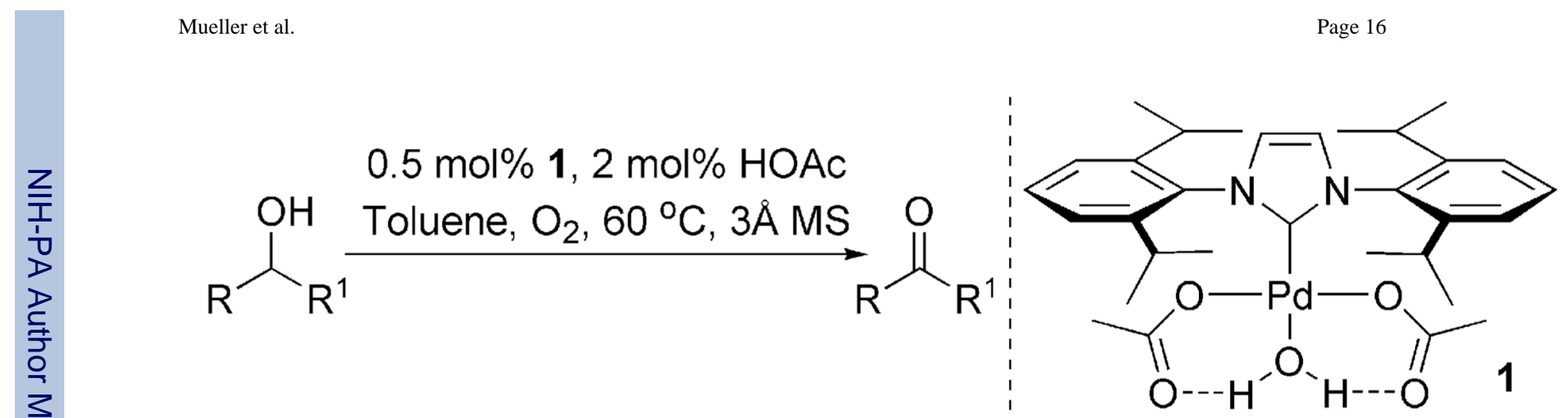

Figure 1.

Optimized alcohol oxidation conditions using catalyst $\mathbf{1}$. 


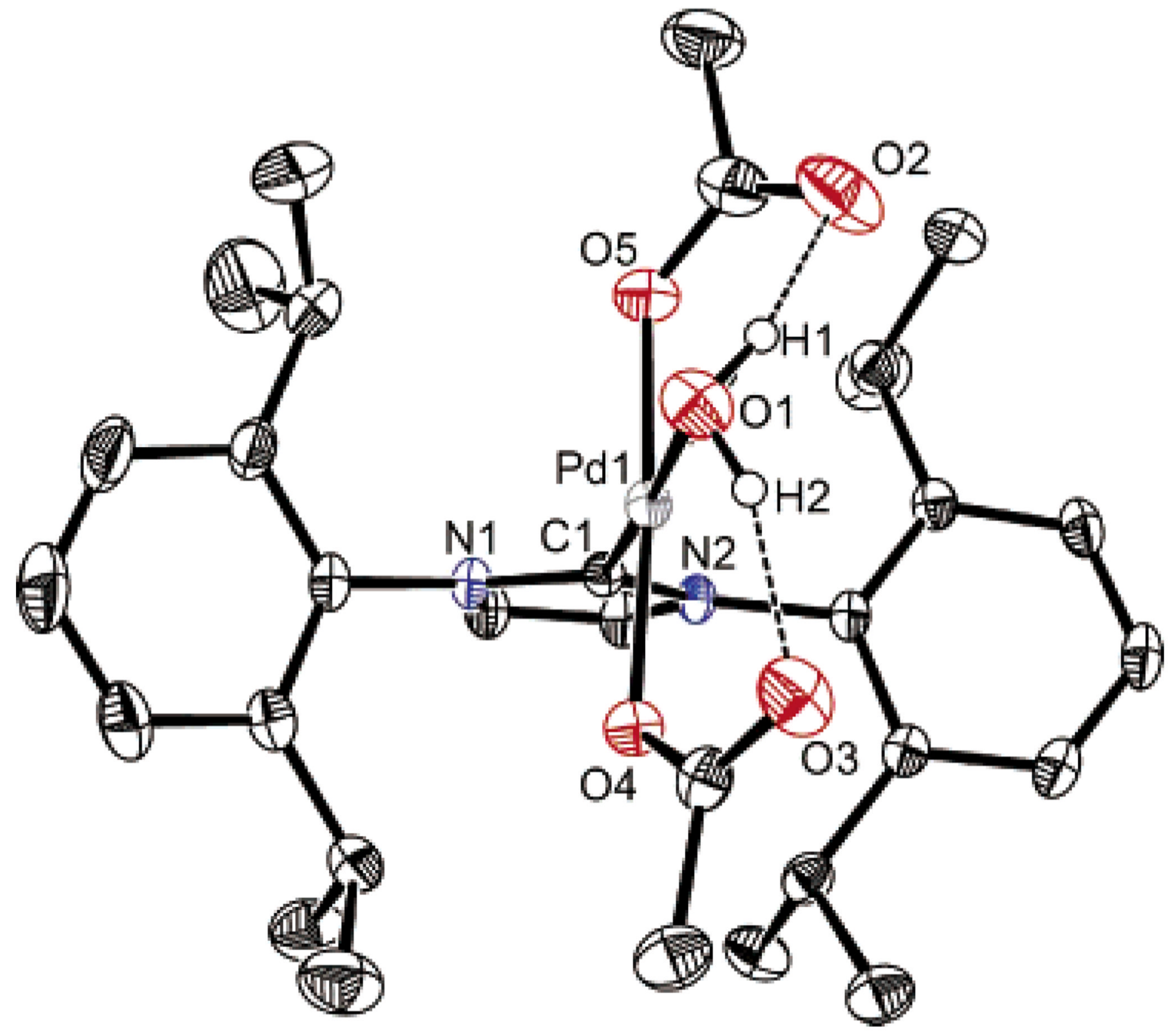

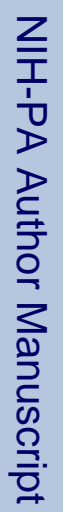

Figure 2.

Ortep representation of $\mathbf{1 .}$ 


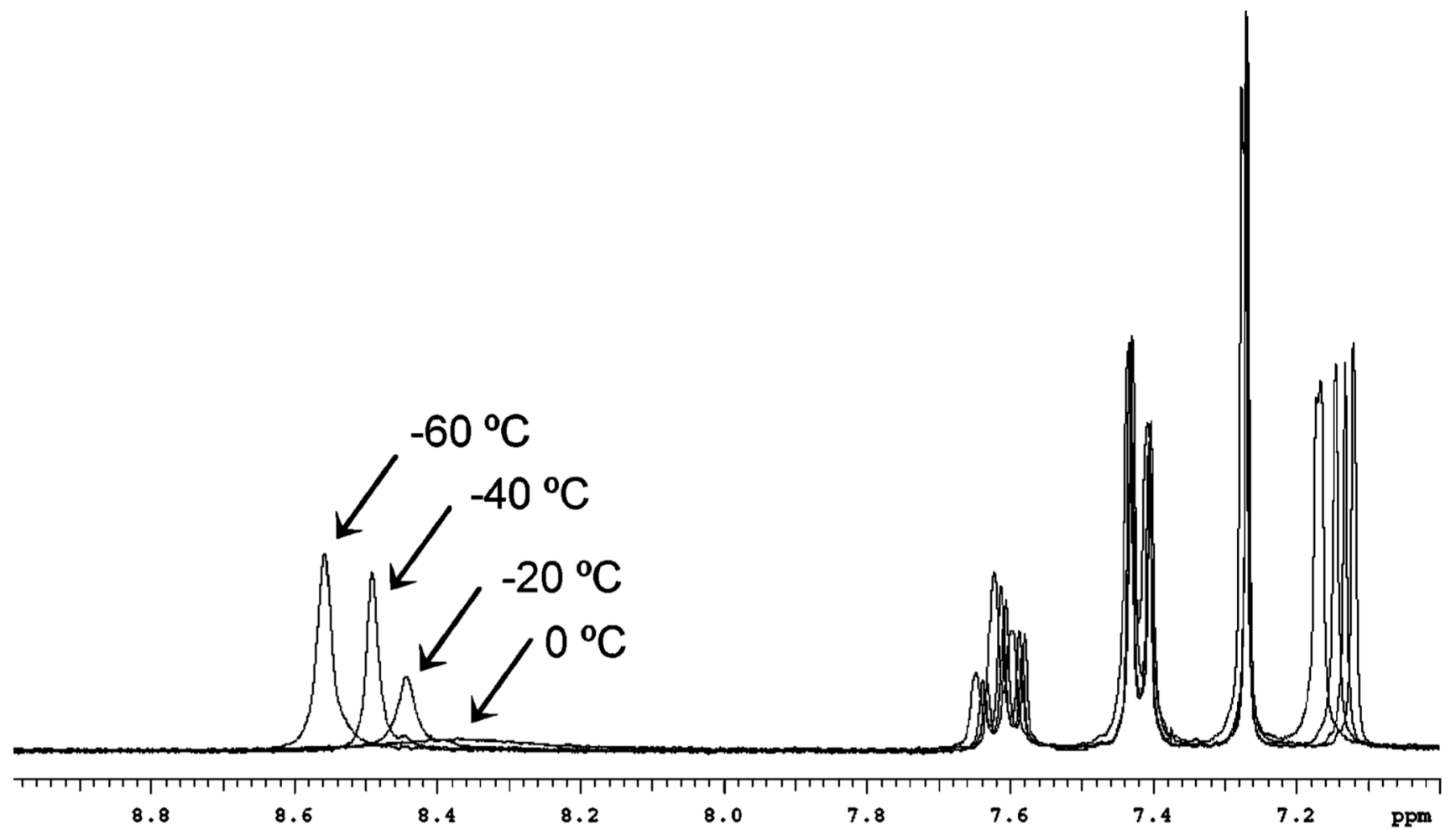

Figure 3.

Overlaid ${ }^{1} \mathrm{H}$ NMR spectra from -60 to $0{ }^{\circ} \mathrm{C}$ of $\mathbf{1}$ in $\mathrm{CDCl}_{3}$. 


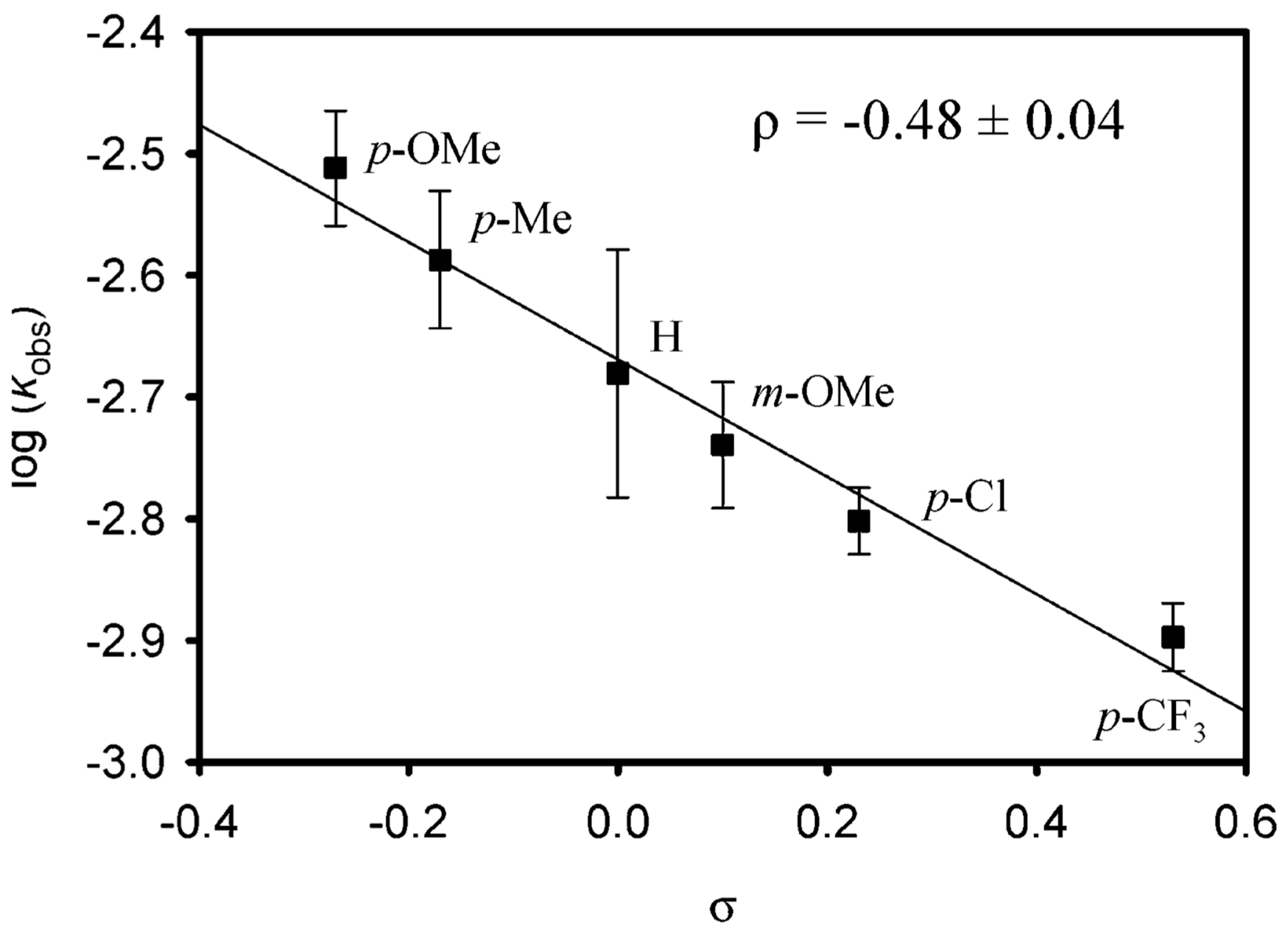

Figure 4.

$\log$ kobs vs $\sigma$ for the oxidation of benzylic alcohols at $50{ }^{\circ} \mathrm{C}$. Conditions: $0.5 \mathrm{~mol} \% \mathbf{1}, 0.45$ $\mathrm{M}$ alcohol, $2 \mathrm{~mol} \% \mathrm{AcOH}$ in benzene, with $3 \AA$ molecular sieves and a balloon charged with $\mathrm{O}_{2}$. 


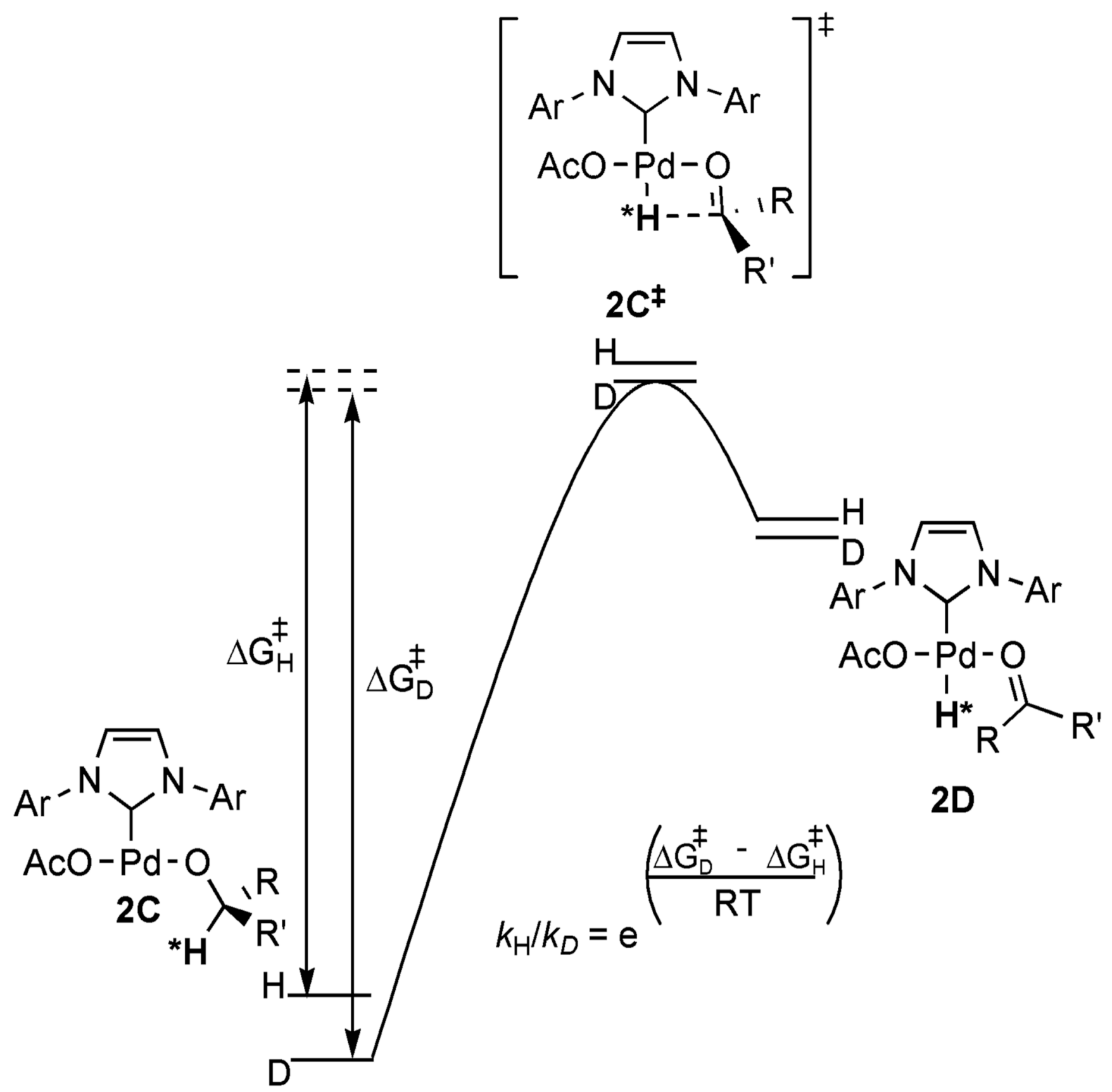

Figure 5.

Transition-state model for $\beta$-hydride elimination using catalyst $\mathbf{1}$. 


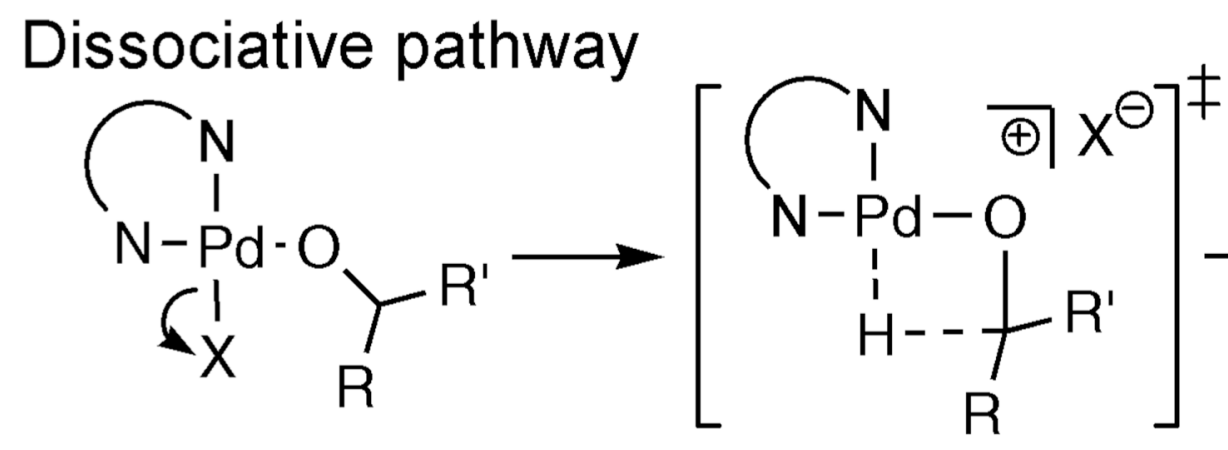

\section{Associative pathway}
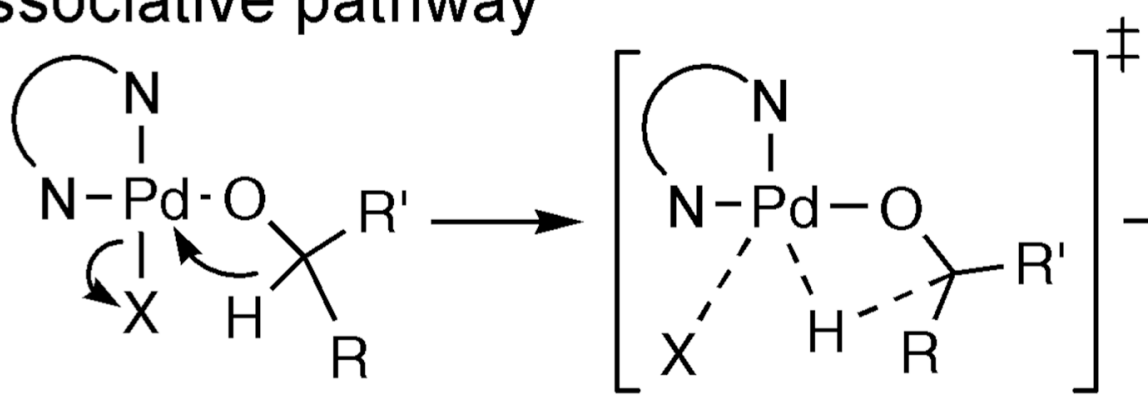

Figure 6.

Limiting pathways for $\beta$-hydride elimination with 4-coordinate Pd. 

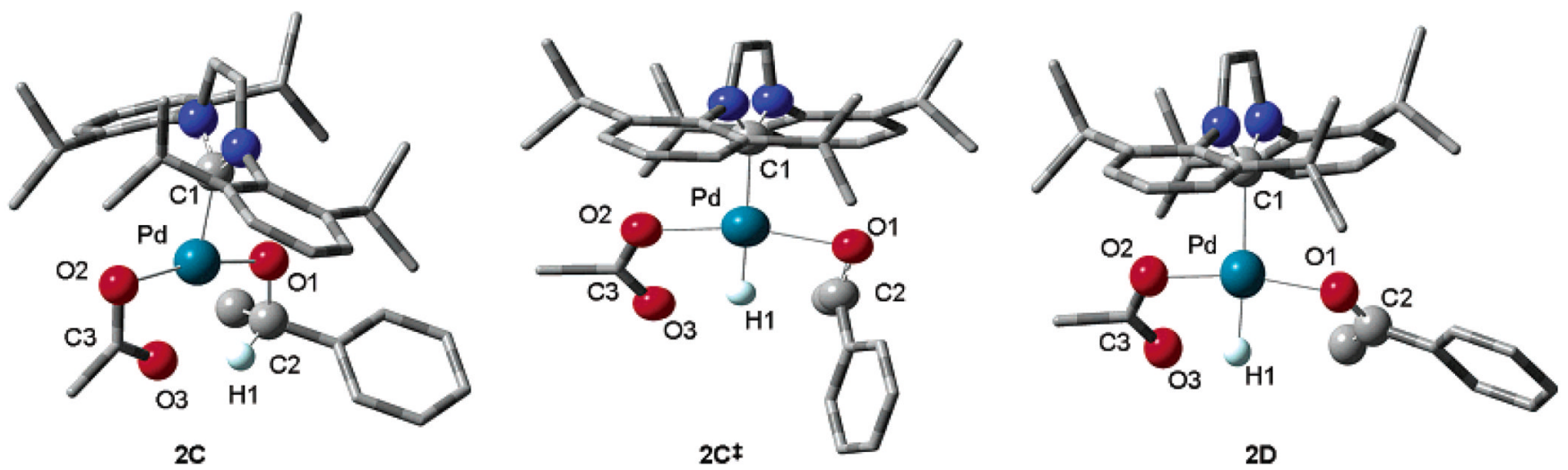

Figure 7.

Optimized ground-state and transition-state structures for the oxidation of sec-phenylethyl alcohol with catalyst 1 using the B3LYP and the LANL2DZ basis sets. 

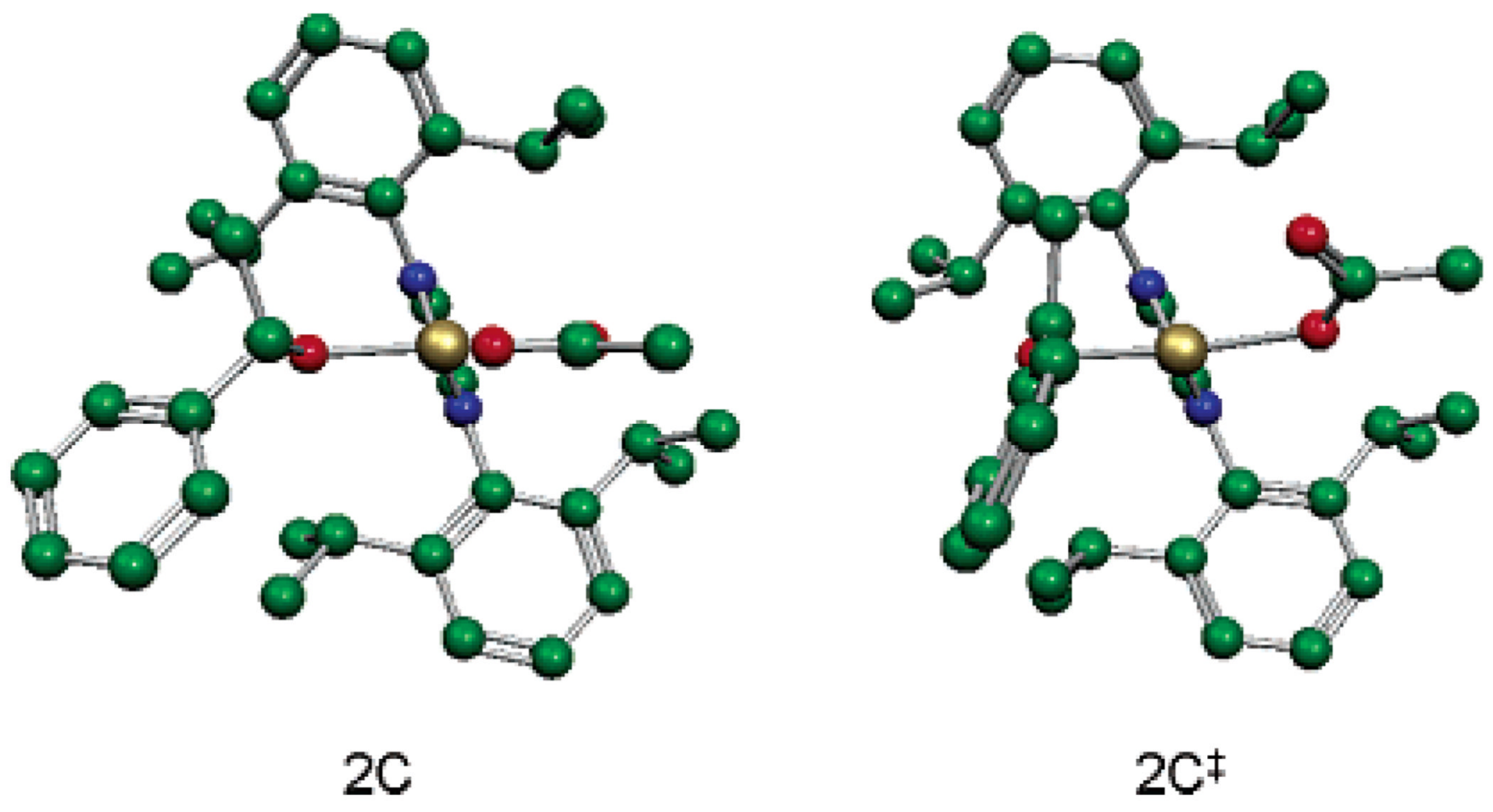

Figure 8.

Translation of the acetate counterion from the ground state to the transition state. Dihedral angles $(\mathrm{C} 1-\mathrm{Pd}-\mathrm{O} 2-\mathrm{C} 3)$ of $\mathbf{2 C}$ and $\mathbf{2} \mathbf{C}^{\ddagger}$ are $181.1^{\circ}$ and $145.1^{\circ}$, respectively. 


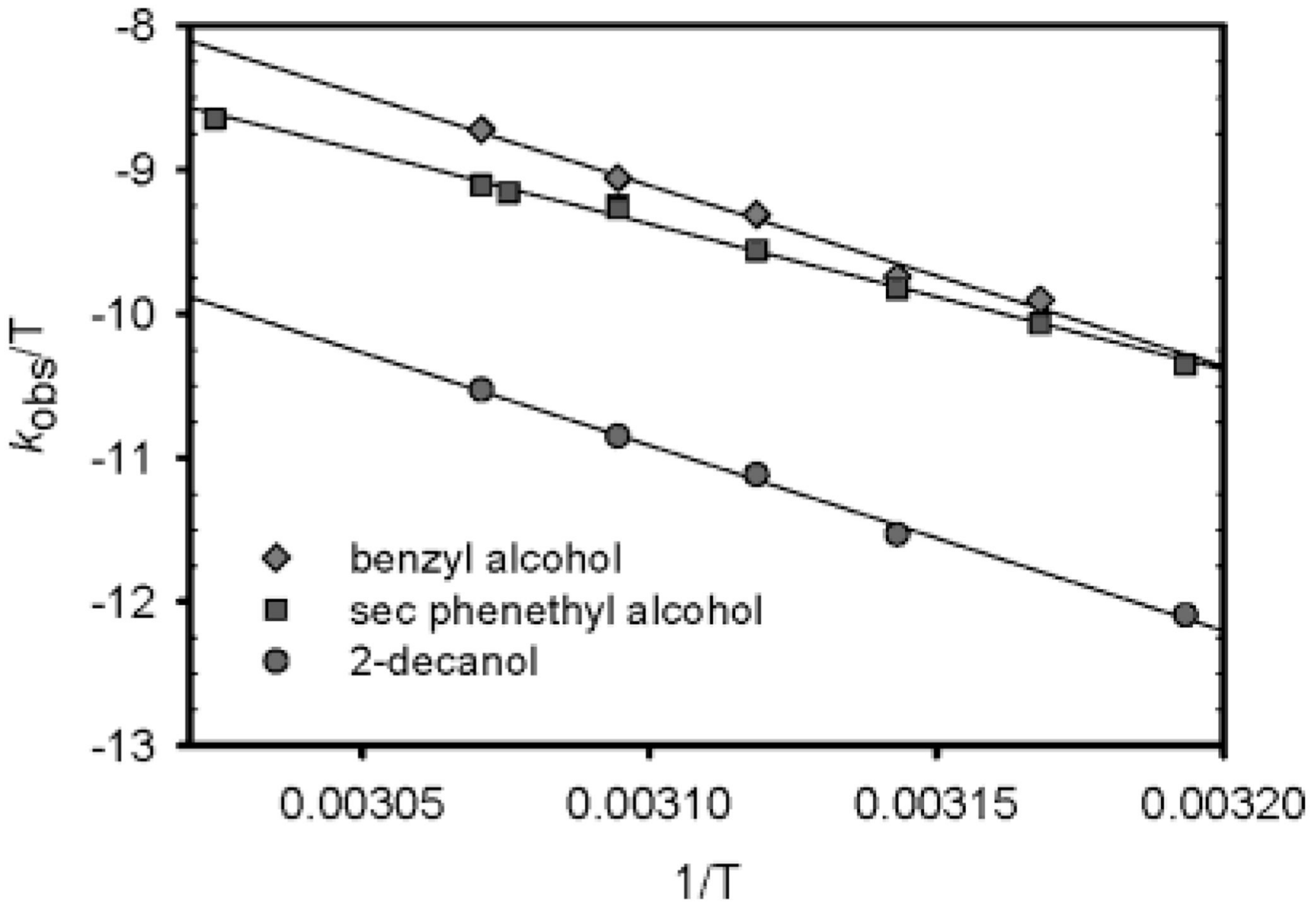

Figure 9.

Eyring plots of benzyl alcohol, sec-phenethyl alcohol, and 2-decanol oxidation using catalyst 1. Conditions: $0.5 \mathrm{~mol} \% 1,0.45 \mathrm{M}$ alcohol, $2 \mathrm{~mol} \% \mathrm{AcOH}$ in benzene, with $3 \AA$ molecular sieves and a balloon charged with $\mathrm{O}_{2}$, temperature range from 40 to $55^{\circ} \mathrm{C}$. 


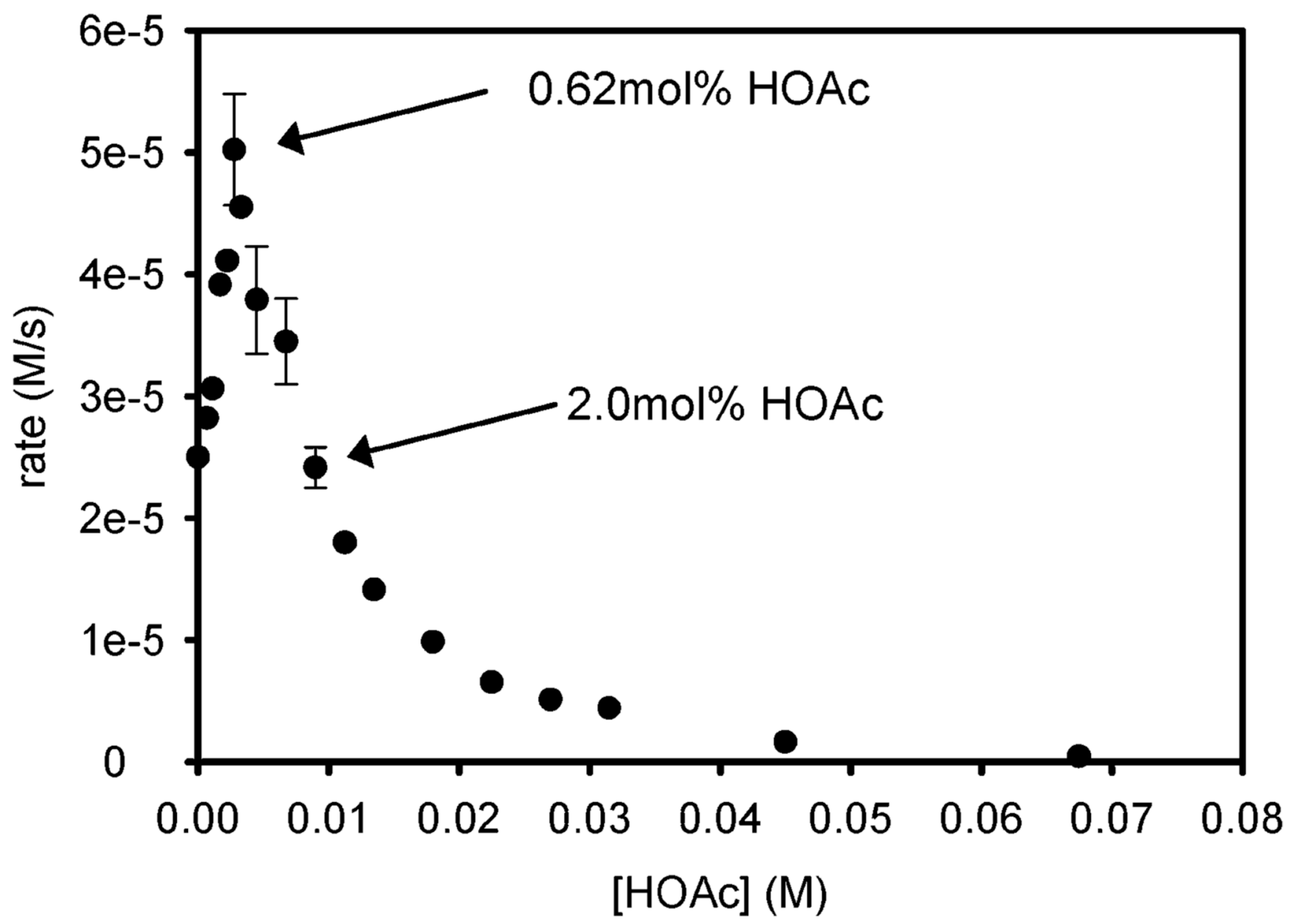

Figure 10.

Rate dependence of sec-phenethyl alcohol oxidation using various HOAc concentrations at 50 ${ }^{\circ} \mathrm{C}$. Conditions: $0.5 \mathrm{~mol} \% \mathrm{1}, 0.45 \mathrm{M}$ alcohol in benzene, with $3 \AA$ molecular sieves and a balloon charged with $\mathrm{O}_{2}$. The range of $[\mathrm{AcOH}]$ is $0-67.5 \mathrm{mM}(0-15 \mathrm{~mol} \%)$. 


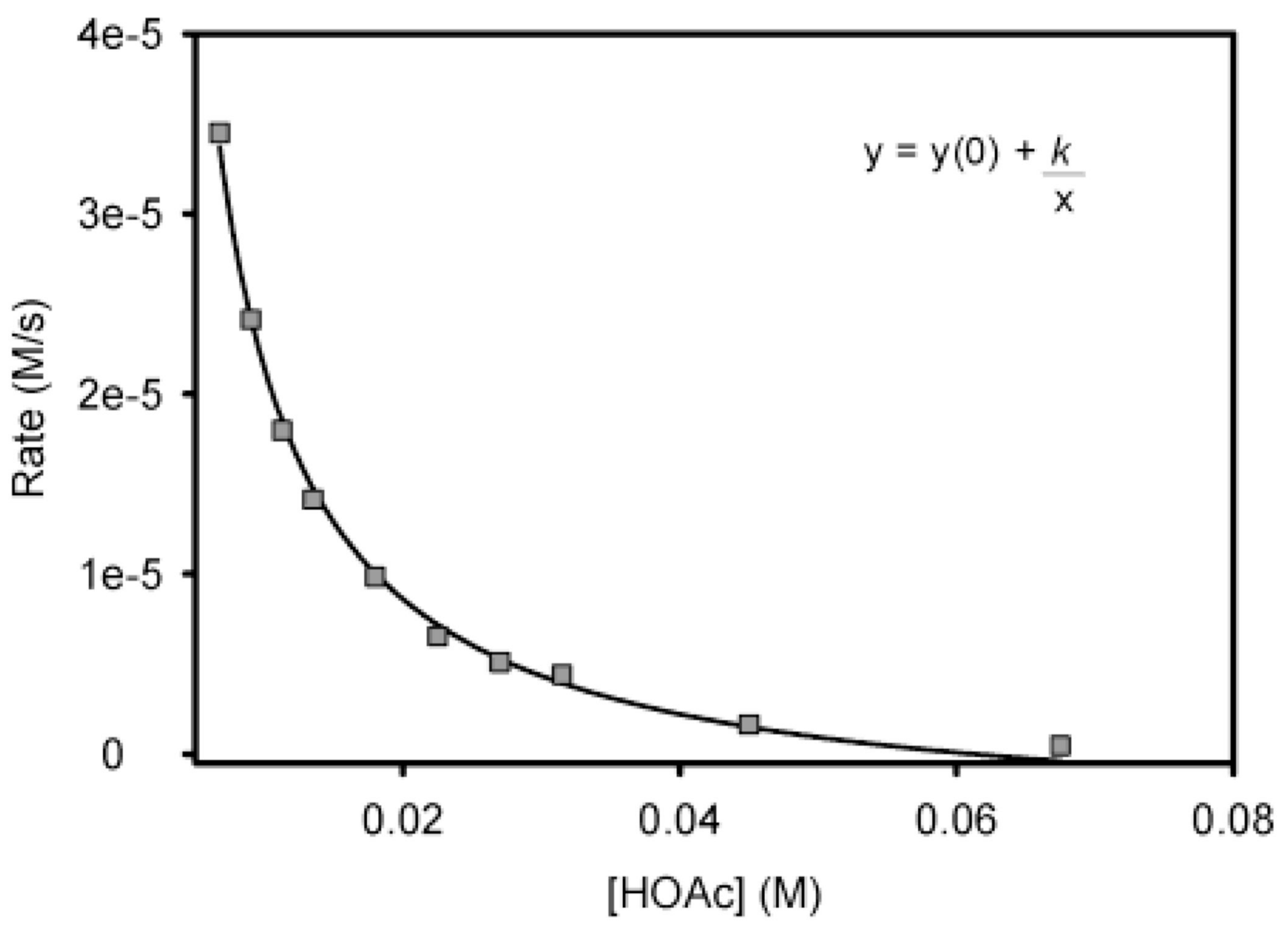

Figure 11.

Inverse first-order rate dependence on [HOAc] for the oxidation of sec-phenethyl alcohol using 1. The plotted range of $[\mathrm{AcOH}]$ is from 6.75 to $67.5 \mathrm{mM}$ (from 1.5 to $15 \mathrm{~mol} \%$ ). 


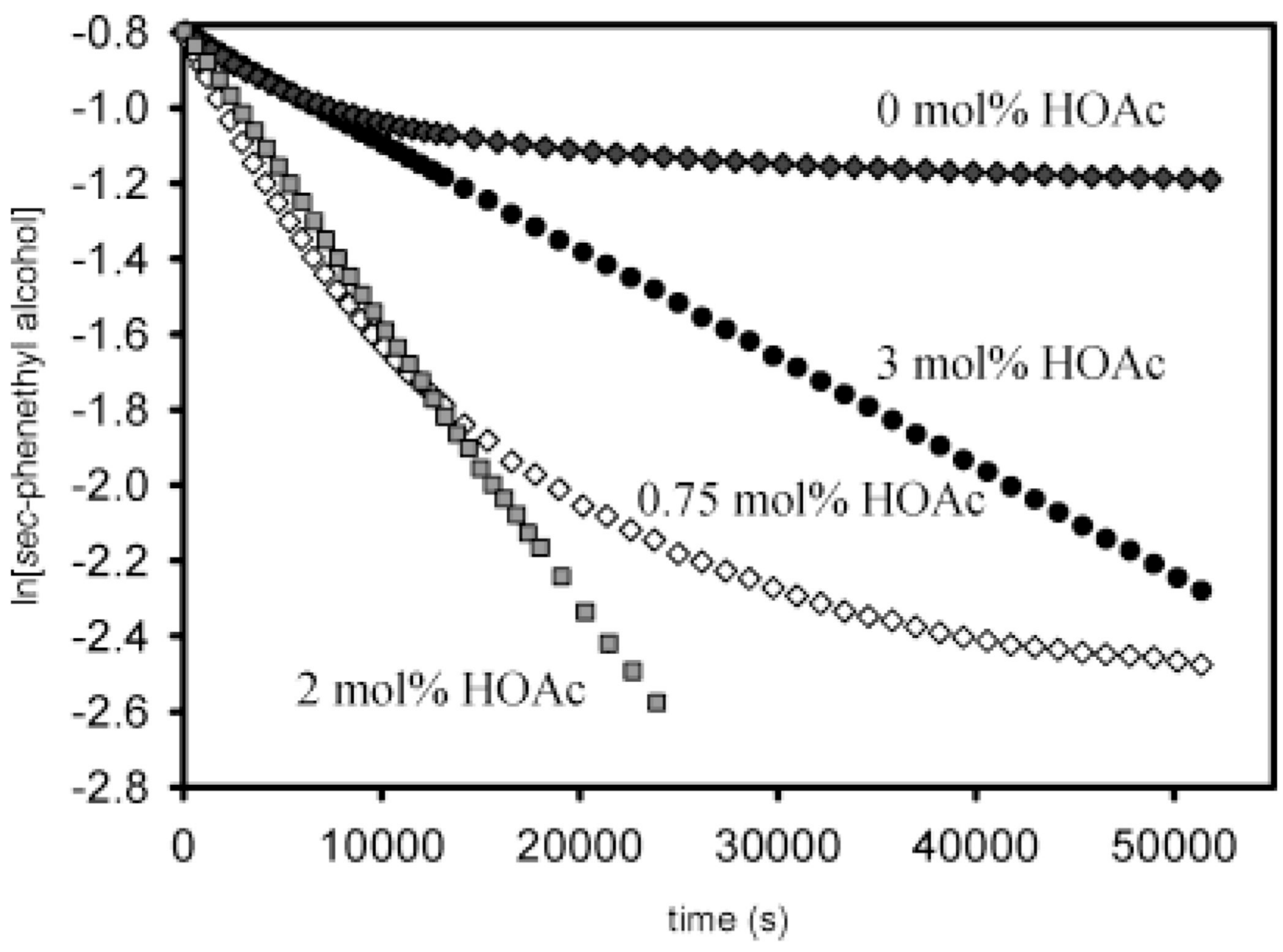

Figure 12.

Natural logarithm of sec-phenethyl alcohol concentration vs time at various HOAc concentrations at $50{ }^{\circ} \mathrm{C}$ (every 10 time points displayed). Conditions: $0.5 \mathrm{~mol} \% \mathbf{1}, 0.45 \mathrm{M}$ alcohol in benzene, with $3 \AA$ molecular sieves and a balloon charged with $\mathrm{O}_{2}$. 


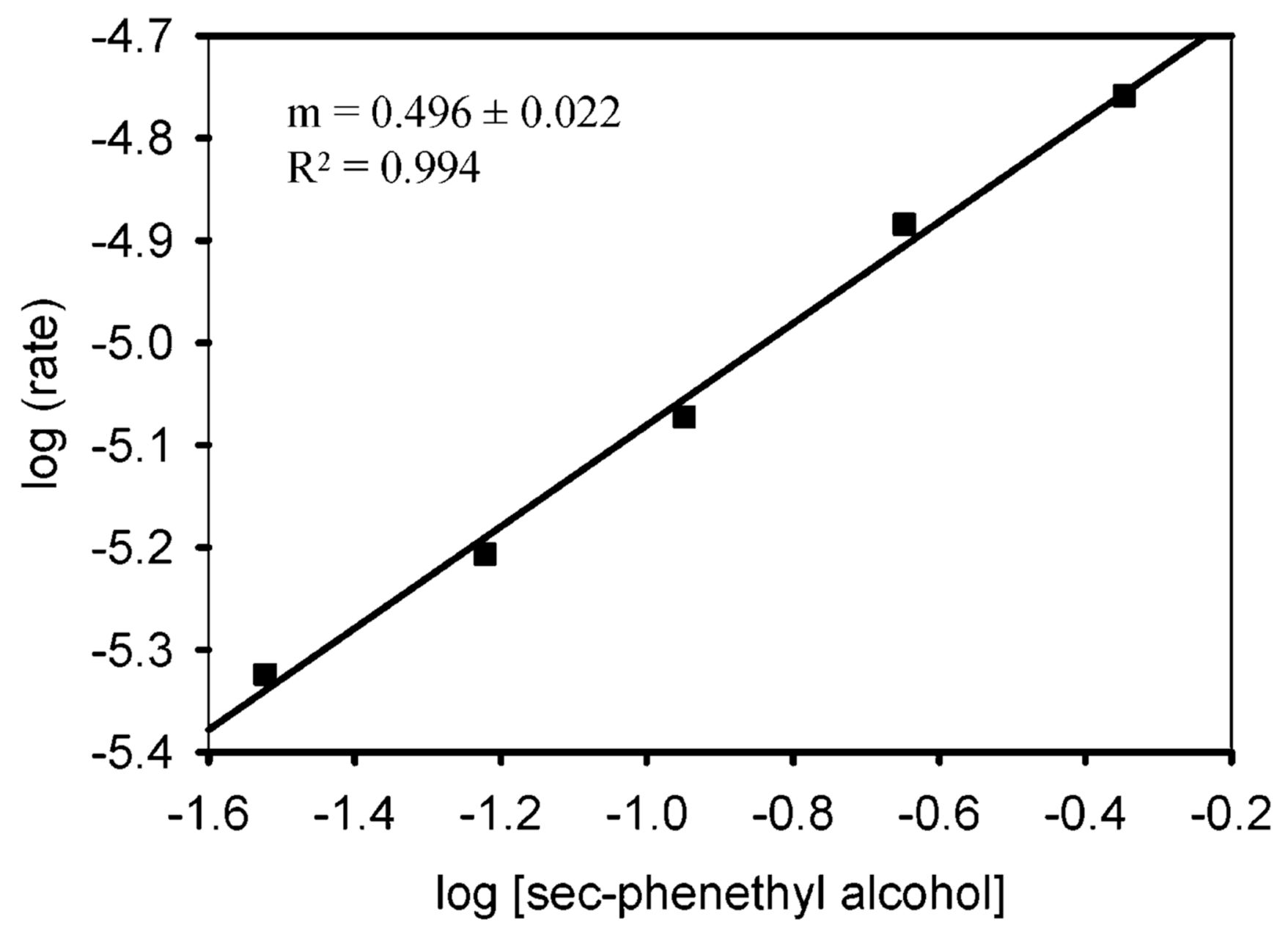

Figure 13.

$\log -\log$ plot of the rate of sec-phenethyl alcohol oxidation vs sec-phenethyl alcohol concentration. Conditions: $2.25 \mathrm{mM} \mathrm{1,0 \%} \mathrm{AcOH}$ in benzene, with $3 \AA$ molecular sieves and a balloon charged with $\mathrm{O} 2$. The range of sec-phenethyl alcohol concentration is from 0.03 to $0.45 \mathrm{M}$. 


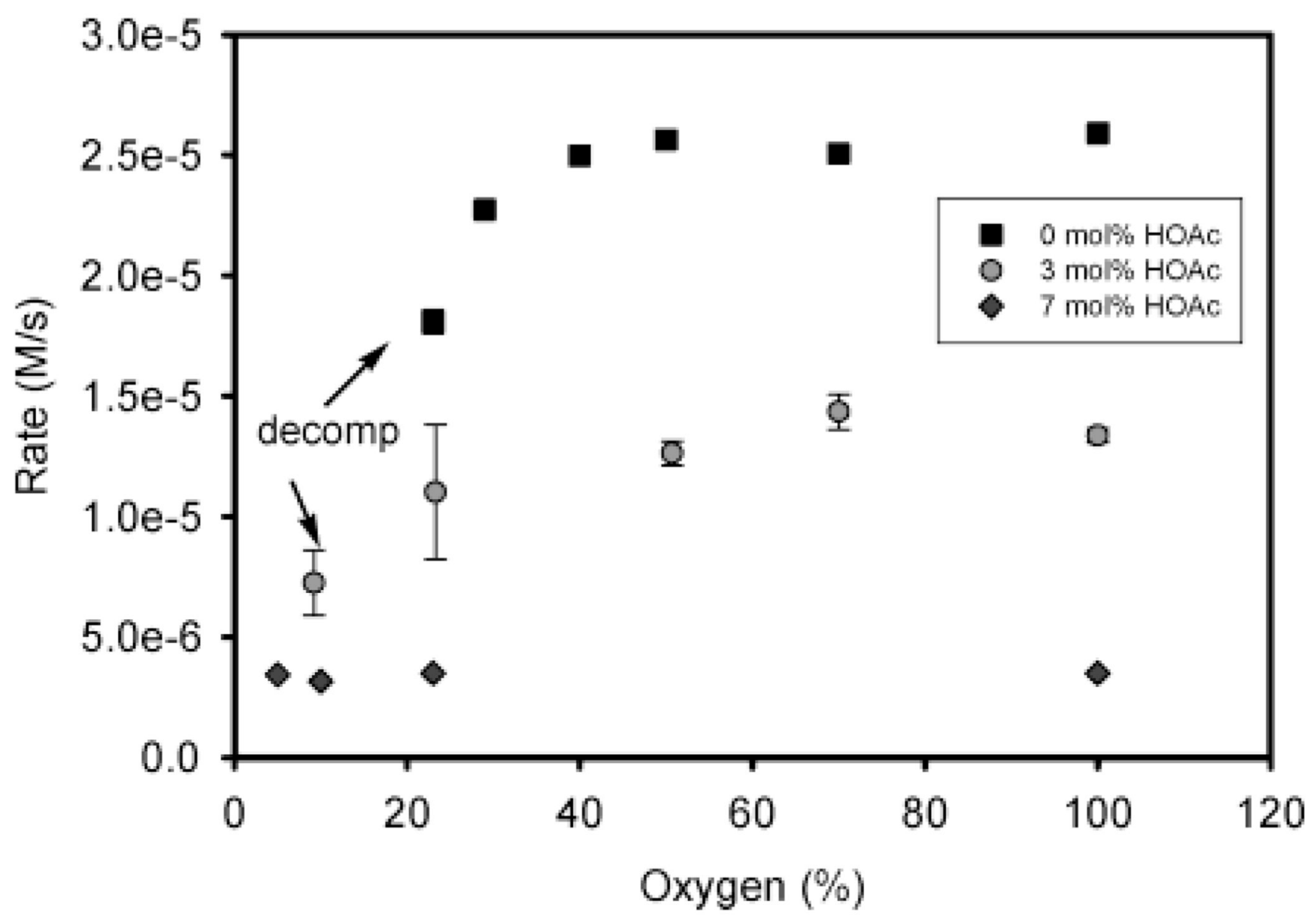

Figure 14.

Initial rates of the sec-phenethyl alcohol oxidation at $50{ }^{\circ} \mathrm{C}$ using various $\mathrm{AcOH}$ concentrations and oxygen/nitrogen mixtures. Conditions: $0.5 \mathrm{~mol} \%$ 1, $0.45 \mathrm{M}$ sec-phenethyl alcohol, with 3 Å molecular sieves and a balloon charged with $\mathrm{O}_{2}$. 


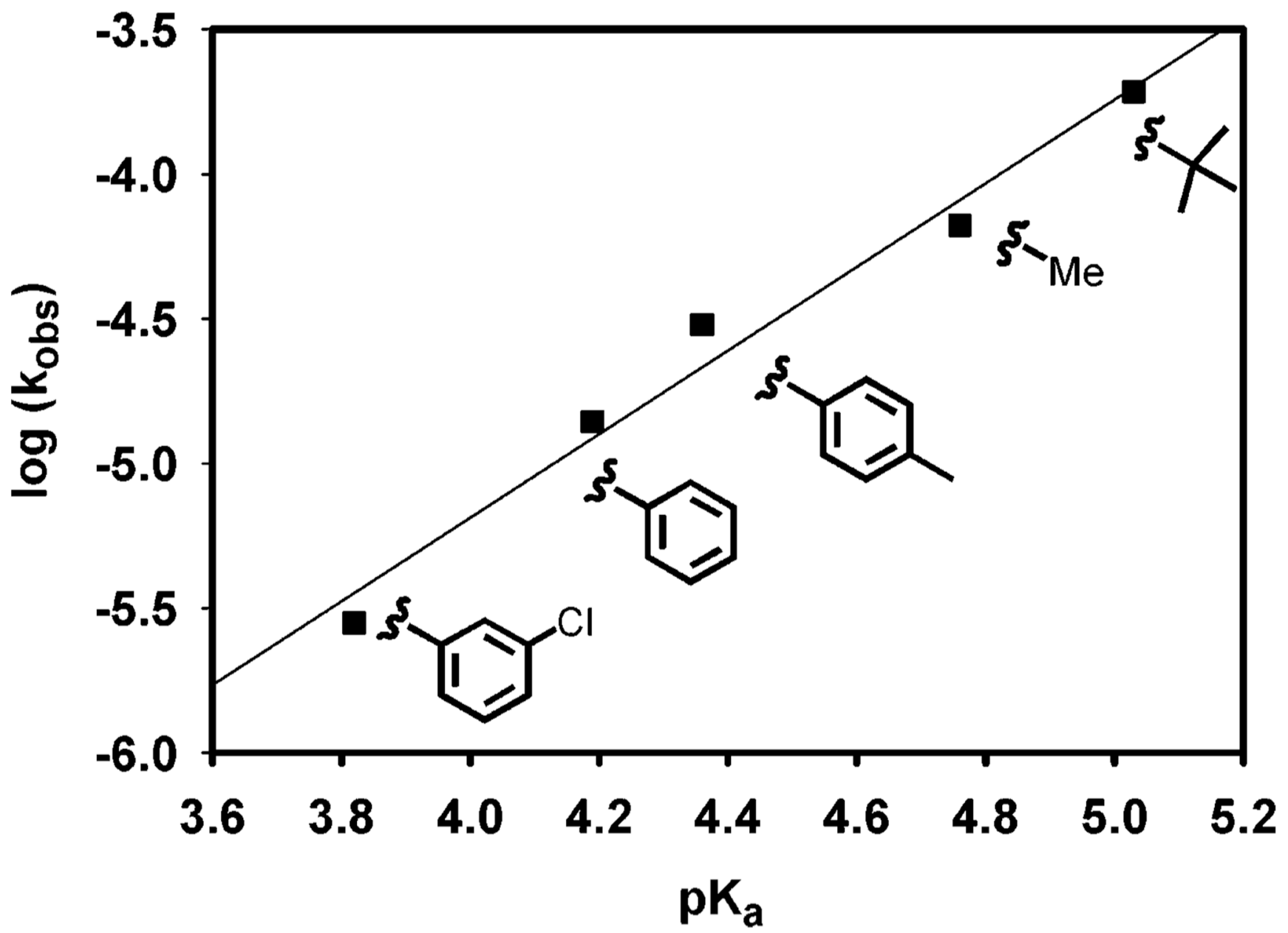

Figure 15.

Brønsted-type plot of alcohol oxidation with a 2 mol \% concentration of the corresponding acid at $50{ }^{\circ} \mathrm{C}$. Conditions: $0.5 \mathrm{~mol} \% \mathrm{Pd}$ catalyst, $0.25 \mathrm{M}$ sec-phenethyl alcohol in benzene, with $3 \AA$ molecular sieves and a balloon charged with $\mathrm{O}_{2}$. 


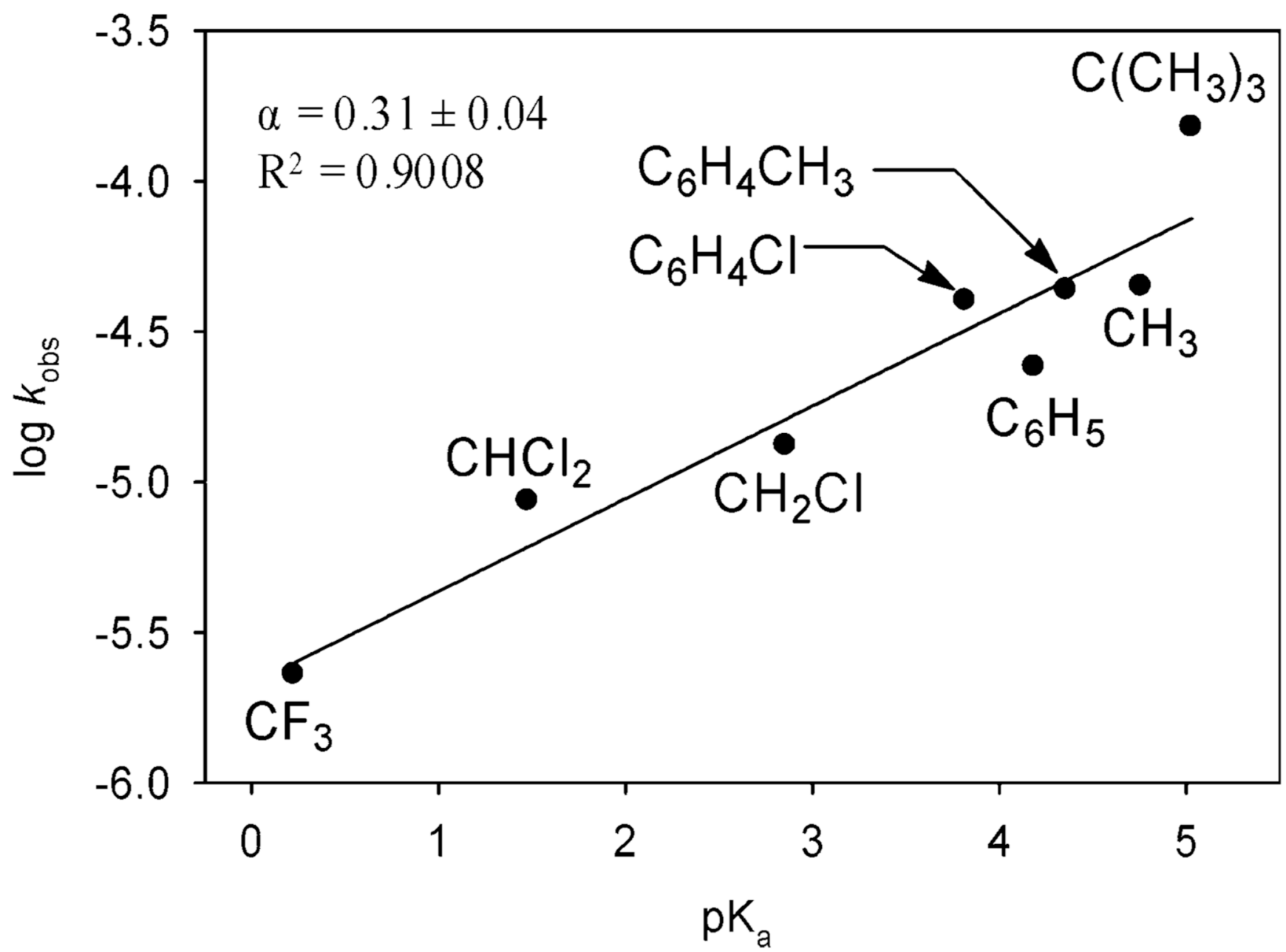

Figure 16.

Brønsted-type plot of alcohol oxidation with 0 mol \% additive acid at $50{ }^{\circ} \mathrm{C}$. Conditions: 0.5 mol \% Pd catalyst, $0.25 \mathrm{M}$ sec-phenethyl alcohol in benzene, with $3 \AA$ molecular sieves and a balloon charged with $\mathrm{O}_{2}$. 

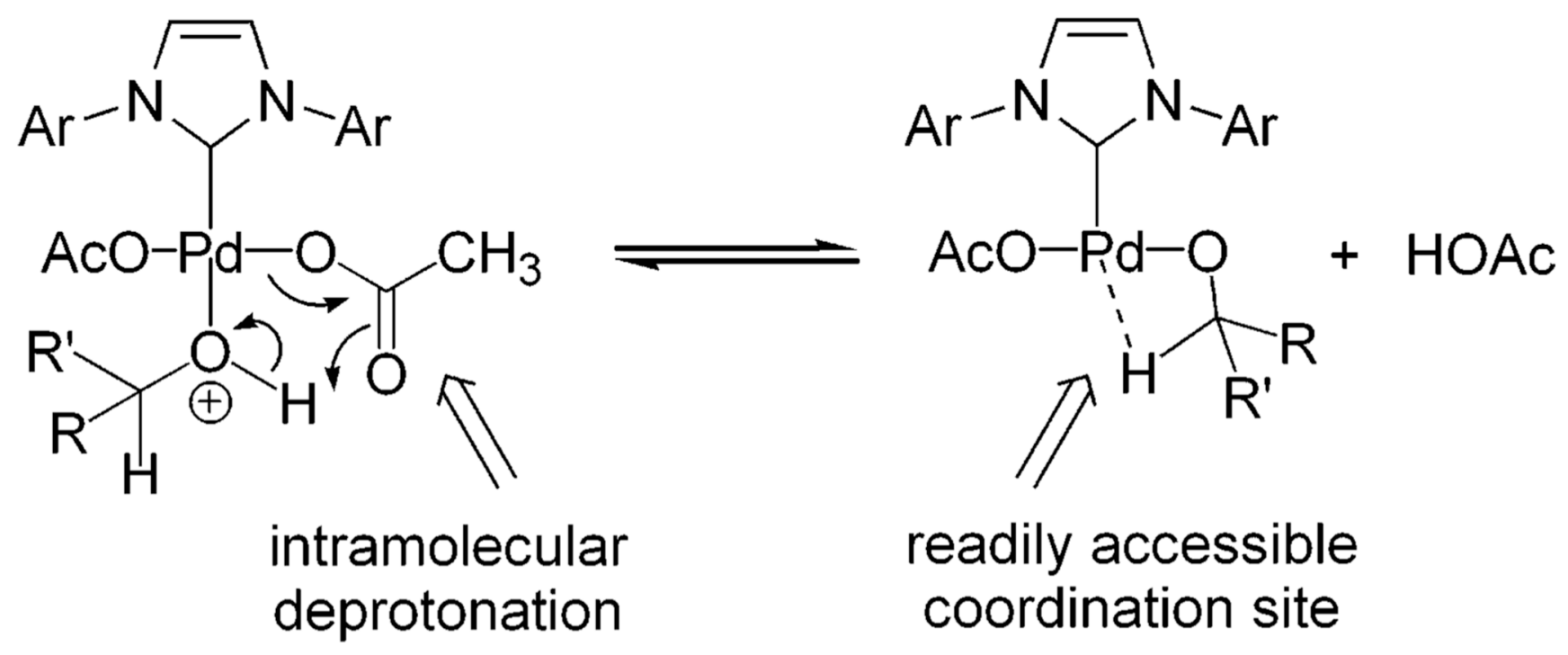

readily accessible coordination site

Scheme 1.

Design of a New Pd(II) Catalyst for Aerobic Oxidation of Alcohols 


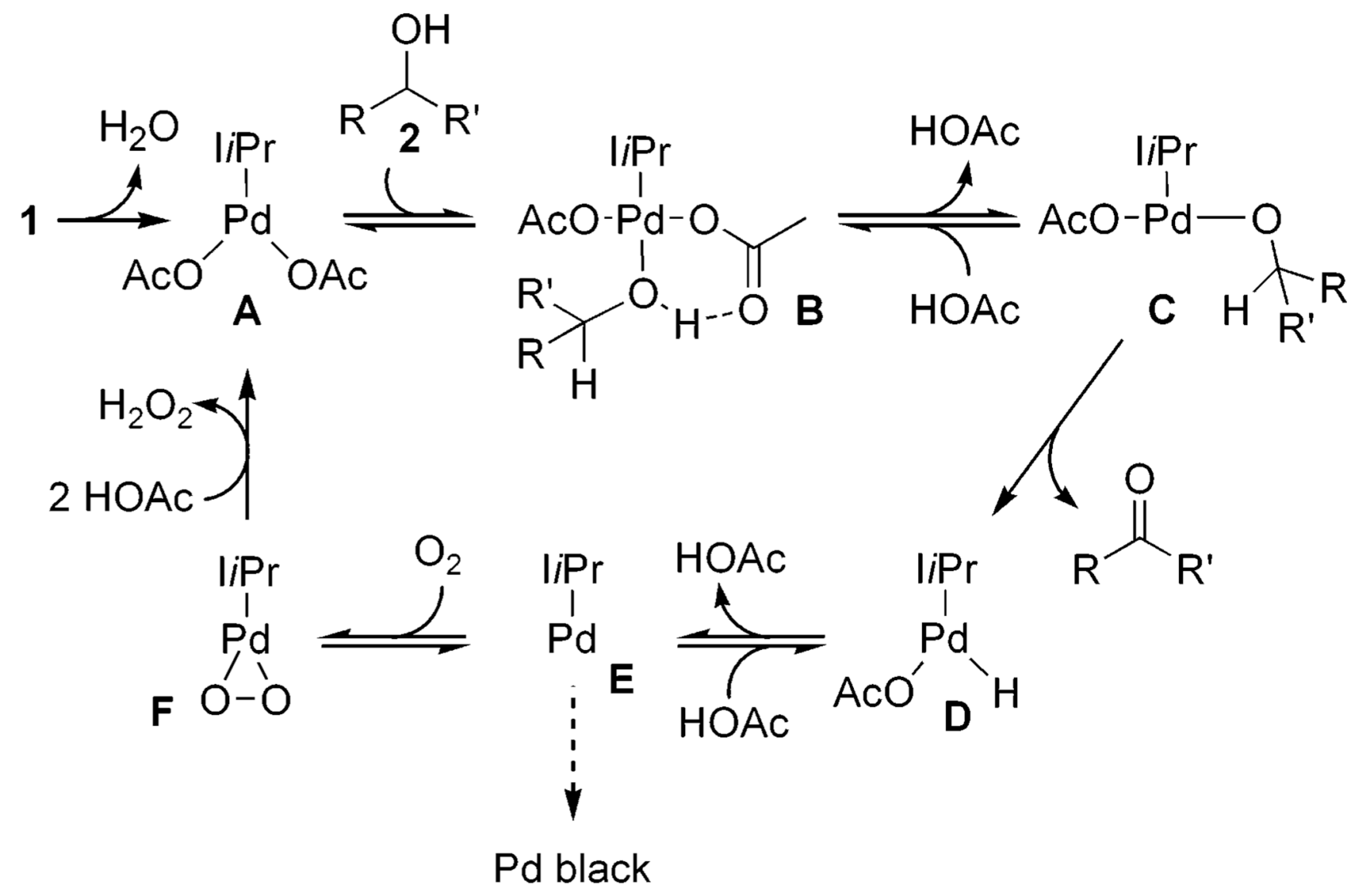

Scheme 2.

A Proposed Mechanism for the Pd(II)-Catalyzed Oxidation of Alcohols Using 1 


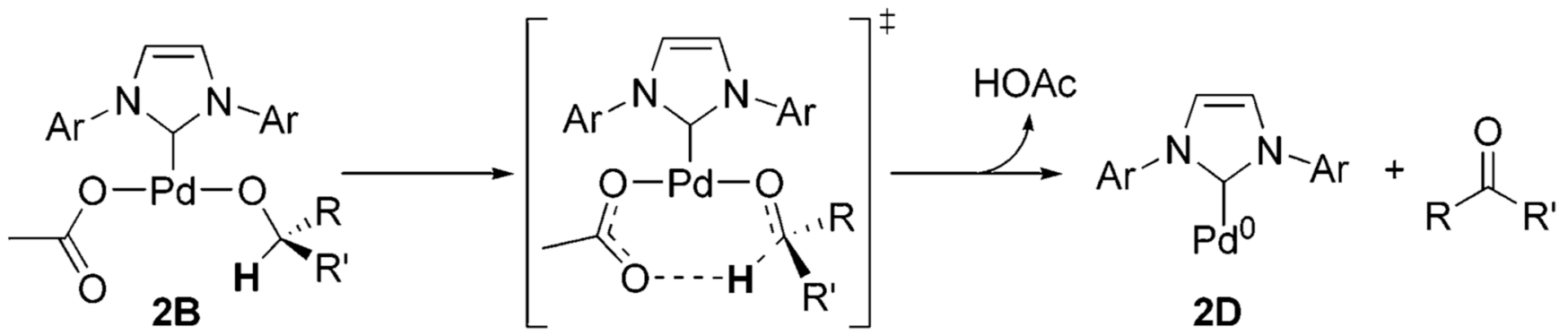

Scheme 3 .

An Unlikely Alternative Scenario That May Lead to a Large KIE 


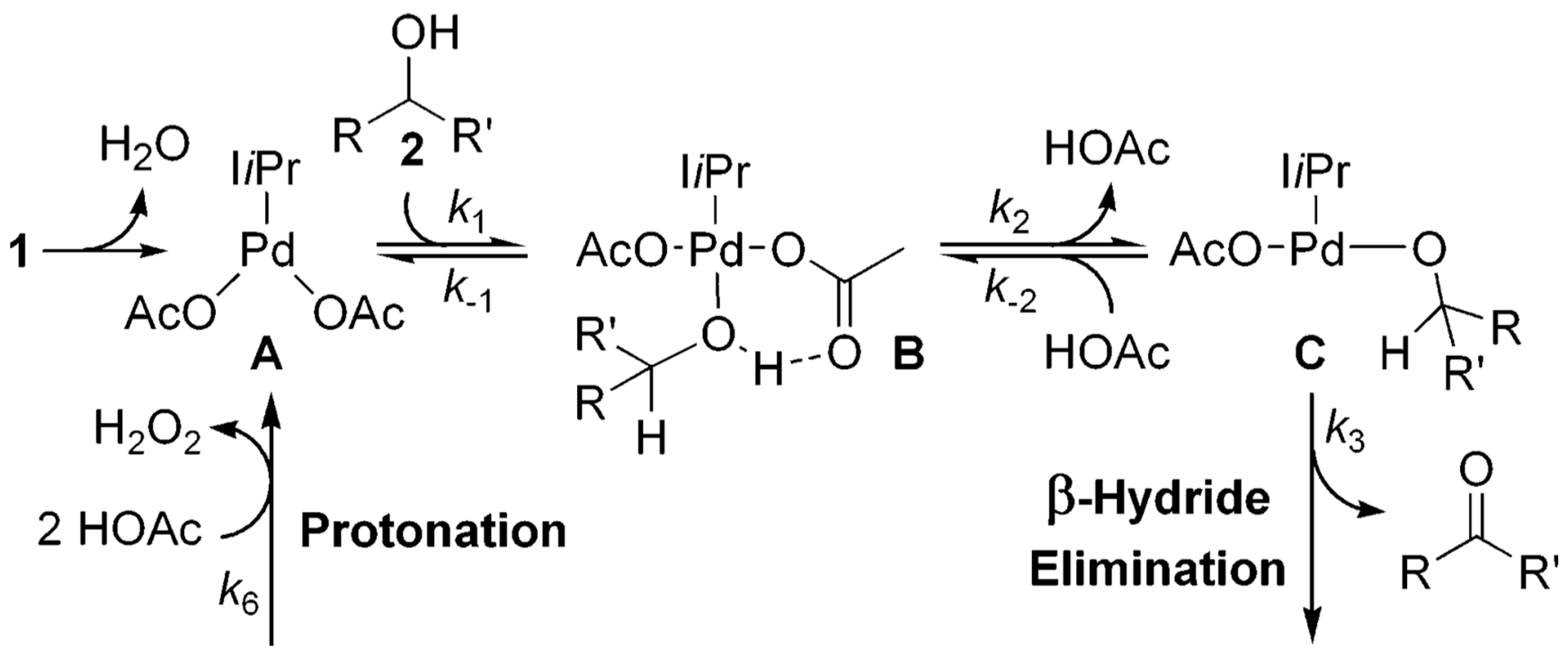<smiles></smiles>
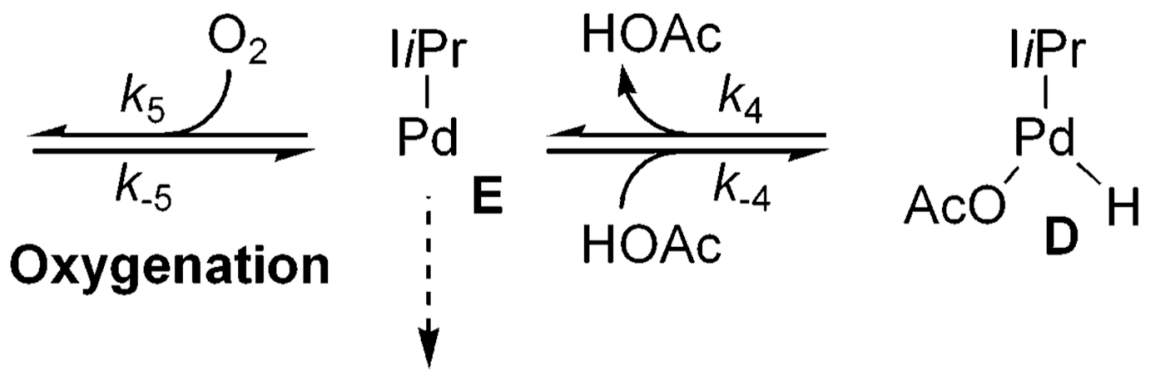

\section{Pd black}

Scheme 4.

Revised Proposed Mechanism: Possible Rate-Influencing Steps of Pd-Catalyzed Aerobic Oxidation 
Table 1

Selected Lengths and Angles of 2C, 2C $\ddagger$, and 2D

\begin{tabular}{|c|c|c|c|}
\hline & $2 \mathrm{C}$ & $2 C^{*}$ & 2D \\
\hline \multicolumn{4}{|c|}{ Lengths $(\AA)$} \\
\hline $\mathrm{Pd}-\mathrm{O} 1$ & 2.00 & 2.17 & 2.14 \\
\hline $\mathrm{Pd}-\mathrm{O} 2$ & 2.18 & 2.07 & 2.06 \\
\hline $\mathrm{Pd}-\mathrm{O} 3$ & 2.23 & 3.11 & 3.14 \\
\hline $\mathrm{Pd}-\mathrm{H} 1$ & 2.70 & 1.60 & 1.57 \\
\hline $\mathrm{C} 2-\mathrm{H} 1$ & 1.10 & 1.97 & 3.01 \\
\hline $\mathrm{C} 2-\mathrm{O} 1$ & 1.48 & 1.31 & 1.28 \\
\hline \multicolumn{4}{|c|}{ Angles (deg) } \\
\hline $\mathrm{Pd}-\mathrm{O} 1-\mathrm{C} 2$ & 110.2 & 89.0 & 123.3 \\
\hline $\mathrm{Pd}-\mathrm{H} 1-\mathrm{C} 2$ & 87.5 & 89.3 & 75.8 \\
\hline $\mathrm{C} 1-\mathrm{Pd}-\mathrm{O} 3$ & 164.1 & 131.2 & 120.2 \\
\hline $\mathrm{O} 1-\mathrm{Pd}-\mathrm{O} 3$ & 106.8 & 116.3 & 123.5 \\
\hline $\mathrm{O} 2-\mathrm{Pd}-\mathrm{O} 3$ & 60.9 & 47.9 & 47.4 \\
\hline $\mathrm{O} 1-\mathrm{Pd}-\mathrm{C} 1$ & 89.0 & 100.4 & 98.6 \\
\hline $\mathrm{C} 2-\mathrm{Pd}-\mathrm{C} 1$ & 103.2 & 95.0 & 92.4 \\
\hline
\end{tabular}


Table 2

Activation Parameters for Alcohol Oxidation at $50{ }^{\circ} \mathrm{C}$ Using Catalyst 1

Substrate 
Table 3

KIE Values at Various HOAc Concentrations

\begin{tabular}{|c|c|c|c|c|c|}
\hline $\begin{array}{l}\text { [HOAc] } \\
(\mathrm{mM})\end{array}$ & $\begin{array}{l}\text { KIE } \\
\text { value }\end{array}$ & $\begin{array}{l}\text { [HOAc] } \\
(\mathrm{mM})\end{array}$ & $\begin{array}{l}\text { KIE } \\
\text { value }\end{array}$ & $\begin{array}{l}\text { [HOAc] } \\
(\mathrm{mM})\end{array}$ & $\begin{array}{l}\text { KIE } \\
\text { value }\end{array}$ \\
\hline 0 & 1.7 & 2.79 & 3.1 & 6.75 & 5.2 \\
\hline 2.12 & 2.7 & 4.50 & 3.4 & 9.00 & 5.5 \\
\hline
\end{tabular}

